\title{
Snowfall and snowpack in the Western U.S. as captured by convection permitting climate simulations: current climate and pseudo global warming future climate
}

\author{
Kyoko Ikeda ${ }^{1}$ Roy Rasmussen ${ }^{1} \cdot$ Changhai Liu ${ }^{1}$ Andrew Newman ${ }^{1} \cdot$ Fei Chen ${ }^{1} \cdot$ Mike Barlage $^{2} \cdot$ Ethan Gutmann ${ }^{1}$. \\ Jimy Dudhia ${ }^{1} \cdot$ Aiguo Dai $^{3} \cdot$ Charles Luce $^{4} \cdot$ Keith Musselman $^{5}$
}

Received: 11 May 2020 / Accepted: 5 May 2021 / Published online: 21 May 2021

(c) The Author(s) 2021

\begin{abstract}
This study examines current and future western U.S. snowfall and snowpack through current and future climate simulations with a 4-km horizontal grid spacing cloud permitting regional climate model over the entire CONtinental U.S. for a 13-year period between 2001 and 2013. At this horizontal resolution, the spatiotemporal distribution of the orographic snowfall and snowpack is well captured partly due to the ability of the model to realistically simulate mesoscale and microphysical features such as orographically induced updrafts driving clouds and precipitation. The historical simulation well captures the observed snowfall and snowpack amounts and pattern in the western U.S. The future climate simulation uses the PseudoGlobal Warming approach, taking the climate change signal from CMIP5 multi-model ensemble-mean difference between 2070-2099 and 1976-2005. The results show that the thermodynamic impacts of climate change in the western U.S. can be characterized considering mountain ranges in two distinct geographic regions: the mountain ranges close to the Pacific Ocean (coastal ranges) and those in the inter-mountain west. Climate change out to 2100 significantly impacts all aspects of the water cycle, with pronounced climate change response in the coastal ranges. A notable result is that the snowpack in the Pacific Northwest is predicted to decrease by $\sim 70 \%$ by 2100 . Trends of this magnitude have already been observed in the historical data and in previous studies. The current Pseudo Global Warming future climate simulation and previous global climate simulations all suggest that these trends will continue to the point that most snowpack will be gone by 2100 in the Pacific Northwest for the most aggressive RCP8.5 climate scenario, even if annual precipitation increases by $10 \%$. Future work will focus on extending the current convective permitting results to a full climate change simulation allowing for dynamical changes in the flow.
\end{abstract}

\section{Introduction}

Water in the western U.S. is a valuable commodity that usually renews annually due to the formation of snowpack in the high mountains every winter. The challenge for water managers is dealing with the large inter-annual variability of snowpack, with little to no snow one year to record amounts in other years. A second challenge is that water withdrawal from ground water sources has been occurring over most of the western U.S., leading the U.S. Bureau of Reclamation to identify sustainability of western water as one of the most important challenges facing the western U.S. (Colorado River Basin Water Supply and Demand Study 2012). This conclusion was reached after examining western water usage as well as statistically downscaled Global Climate Model (GCM) future climate simulations over the Western U.S. This important study provided some of the first estimates 
of the impact of climate change on water over the western U.S. The limitation of this approach, however, is that the climate has to be assumed to be stationary (same statistical relationships in the future as in the past). The current study examines snowfall and snowpack over the main western U.S. mountain ranges using dynamical downscaling for both the historical and future climate, where the future climate focus is on thermodynamical changes by using a Pseudo Global Warming (PGW) approach (Schär et al. 1996).

Dynamical downscaling estimates clouds and precipitation over complex terrain through direct modeling of the physical processes. Since statistical downscaling uses the same statistics for the future climate as developed from the current climate simulation, this may not adequately capture mesoscale changes to the precipitation (Gutmann et al. 2012). In addition, statistical downscaling is only as good as the quality and coverage of the gridded observations used to downscale the global climate model to. Gutmann et al. (2014) has shown that this can be problematic over many mountain ranges in western U.S. due to the poor coverage of observation data over complex terrain.

The present study examines current and future western U.S. snowfall and snowpack by performing a very highresolution climate simulation with $4 \mathrm{~km}$ horizontal resolution over the entire CONtinental U.S. (CONUS, Liu et al. 2017). At this horizontal grid spacing orographic snowfall and snowpack are well captured in space and time due to the ability of the model to simulate mesoscale features such as orographically induced updraft strength driving clouds and precipitation (Ikeda et al. 2010; Rasmussen et al. 2011, 2014). In addition, most atmospheric convection is well represented without the need of a convective parameterization (Weisman et al. 1997; Prein et al. 2017) at this horizontal grid spacing.

The future western U.S. snowfall and snowpack is examined using a Pseudo Global Warming approach (PGW, Schär et al. 1996). This was necessary due to the large computer time needed to run an ensemble approach for kilometer scale horizontal resolution. As a result, sub-monthly dynamical changes are not captured in this study. Instead, the results largely focus on thermo-dynamical changes in a future climate by using the average forcing from 19 CMIP5 models (Taylor et al. 2012). Further details on this approach are given in Sect. 2.

Most regional dynamical downscaling studies use resolutions of $25 \mathrm{~km}$ or larger, or cover limited regions of the western U.S. (Hughes et al. 2012, 2014; Rhoades et al. 2017). This study increases the horizontal model resolution by a factor of six or more over previous studies and extends the region to the entire continental U.S. (Liu et al. 2017). The advantage of this approach is that it is able to accurately capture precipitation and snowfall over the wide variety of mountainous terrain without the need to perform statistical downscaling. For instance, Ikeda et al. (2010) and Rasmussen et al. (2011) note that the ability of a model to accurately estimate snowfall depends on the dominant wavelengths of the mountainous terrain, with the Colorado Rocky Mountains needing resolutions less than 6-km grid spacing to adequately capture orographically induced cloud updrafts and associated precipitation within $10 \%$ of observations. Other regions (such as the mountains in Idaho), have more complex terrain requiring even smaller resolutions (unpublished work).

Our verification with Snowpack Telemetry (SNOTEL) data (Serreze et al. 1999; http://www.wcc.nrcs.usda.gov/ snow/) shows that $4-\mathrm{km}$ grid spacing is able to capture monthly snowfall and snowpack over all major mountain ranges in the western U.S. within $~ 10 \%$ of observations (in Sect. 2). The recent study by Beck et al. (2019) shows that the 13-year CONUS simulation provides an excellent estimate of the spatial and temporal structure of precipitation in the western U.S. as compared to 15 other methods.

The disadvantage of the current high-resolution approach is the high computer expense, and thus only one future climate scenario is presented in contrast to studies with $25 \mathrm{~km}$ or coarser horizontal resolution (e.g., Rhoades et al. 2017), which compared multiple model simulations of snowpack over the western U.S. using GCMs and RCMs. However, both approaches provide complementary information and are consistent in their prediction of significant future climate changes over the western U.S.

The current work is an expansion of our previous studies on winter snowfall and snowpack over the Colorado Headwaters (Ikeda et al. 2010; Rasmussen et al. 2011, 2014; Chen et al. 2014). These prior studies enabled us to determine the proper model configuration (including horizontal grid spacing) to accurately capture snowfall and snowpack over the complex terrain of the Rocky Mountains. While additional improvements to the model and its configuration were made by Liu et al. (2017) to expand the simulations to the entire Western U.S., these initial studies provided a strong foundation for the current work.

Section 2 discusses the approach used to create the CONUS model simulations while Sect. 3 discusses verification of the model simulations. The primary mountain ranges used in this study and verification of the model results with SNOTEL data are presented in Sect. 4. Section 5 presents the key results including an analysis of water cycle components of snowfall and over the eight major mountain ranges for both current and future climate. Section 6 provides an analysis of the future snowfall and snowpack across the mountain ranges of the western U.S. and Sect. 7 an analysis of seasonal change in snowfall and snowpack. A comparison to previous studies is given in Sect. 8. Section 9 presents conclusions. 


\section{Description of model simulation of current and future climate over CONUS}

Rasmussen et al. (2011) present results of high resolution Weather Research and Forecasting model (WRF; Powers et al. 2017) simulations for the Colorado Headwaters region at 4-km grid spacing using a domain centered on the Colorado Rockies (Ikeda et al. 2010; Liu et al. 2011; Rasmussen et al. 2014). The so-called "CONUS simulations" expand the limited Colorado Headwaters computational domain to nearly North American scale and allows us to compare and contrast snowfall and snowpack in the various major mountain barriers (Liu et al. 2017). Details of the simulation are given in Liu et al. (2017). In the following we briefly describe the model setup and numerical simulations.

\subsection{Setup}

The Weather Research and Forecasting (WRF) model Version 3.4.1 was configured with a domain size of $1360 \times 1016$ points, using a $4-\mathrm{km}$ spacing to cover the CONUS and portions of Canada and Mexico (Fig. 1a). The total domain size is $5440 \mathrm{~km}$ in the east-west and $4064 \mathrm{~km}$ in the north-south. There are 51 stretched vertical levels capped at $50 \mathrm{hPa}$. The parameterization schemes employed are the Thompson microphysics (Thompson and Eidhammer 2014; Thompson et al. 2008), the Yonsei University (YSU) planetary boundary layer scheme (Hong et al. 2006), the Rapid Radiative
Fig. 1 a WRF model domain $(5440 \mathrm{~km} \times 4064 \mathrm{~km})$ at a 4-km grid spacing showing topographic elevation in meters with red rectangles showing the area of focus in this study. $\mathbf{b}$ SNOTEL site locations (colored dots) and eight sub-regions (rectangles). Dots are color-coded by site elevation. Numbers in the parenthesis are the number of sites having data from 2000 to 2013. Photos of a precipitation gauge and snow pillow at a typical SNOTEL site are shown on the right side of the figure (a)
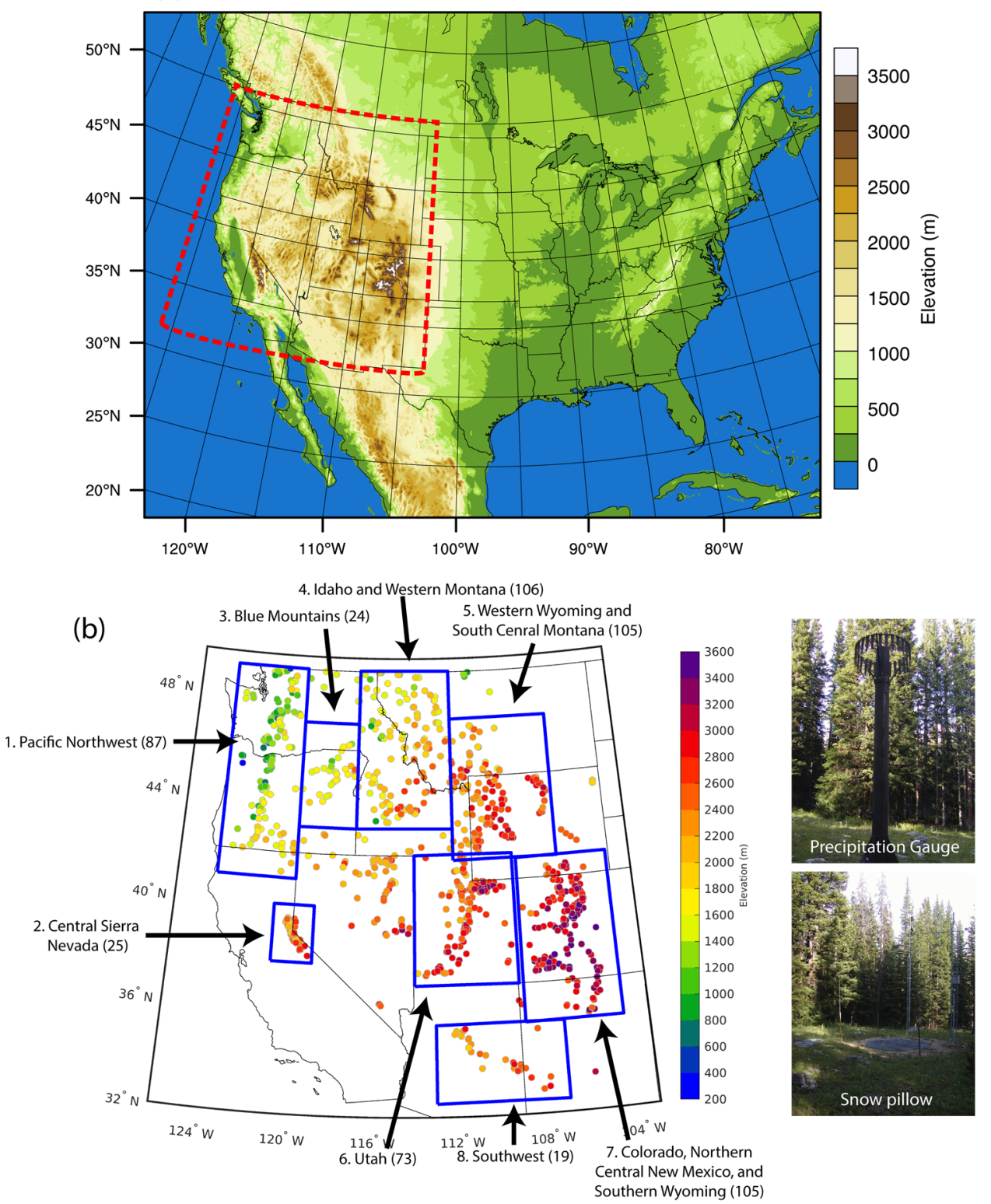
Transfer Model (RRTMG) (Iacono et al. 2008), and the improved Noah-MP land-surface model (Niu et al. 2011). Additionally, spectral nudging is applied and an upgraded lake water temperature treatment is implemented.

\subsection{Numerical experiments}

Two 13-year numerical experiments were conducted using the National Center for Atmospheric Research (NCAR) Yellowstone (CISL 2017) computational resources provided by a NCAR Computation Information Systems Laboratory scientific computing grant. The first experiment was a retrospective/control simulation intended to reproduce the observed weather and climate between 1 October 2000 and 30 September 2013. This simulation was forced with 6-hourly 0.7-degree ERA-Interim reanalysis data (Dee et al. 2011). Tests showed acceptable results when WRF at 4-km grid spacing is one way nested with the $\sim 75 \mathrm{~km}$ resolution reanalysis data (Liu et al. 2017).

The second simulation was a perturbation or climate sensitivity experiment, closely following the Pseudo Global Warming (PGW) approach used in prior Colorado Headwaters work (Rasmussen et al. 2011, 2014) and is described in detail in Liu et al. (2017). This 13-year future simulation was forced with 6-hourly ERA-Interim reanalysis (October 2000-September 2013) plus a climate perturbation:

$\mathrm{WRF}_{\text {input }}=\mathrm{ERA}-$ Interim $_{2000-2013}+\Delta \mathrm{CMIP}_{\mathrm{RCP} 8.5}$

where $\Delta$ CMIP5 $5_{R C P 8.5}$ is the 30 -year CMIP5 multi-model ensemble-mean monthly change signal under the RCP8.5 emission scenario:

$\Delta \mathrm{CMIP}_{\mathrm{RCP} 8.5}=\mathrm{CMIP}_{2070-2099}-\mathrm{CMIP}_{1976-2005}$

In order to minimize the influence of unforced natural climate variations and model-errors in quantifying the forced climate response to future GHG forcing, an ensemble-mean monthly climate change forcing was created from 19 CMIP5 models selected on the basis of their horizontal grid resolution and performance in simulating the North America climate for the late twentieth century (see Table 1 in Liu et al. 2017 for the selected models). The use of a multimodel ensemble mean forcing improves the single-modelrun method applied in our prior PGW simulations (e.g., Rasmussen et al. 2011). The 19 CMIP5 model ensemble mean climate difference at 700-hPa between 1976-2005 and 2070-2099 showed comparable climates as evident by rather weak wind and geopotential perturbations (Fig. 2 in Liu et al. 2017), i.e., weak circulation changes. While the PGW approach does not capture sub-monthly variability of future storm tracks, examination of current climate storm tracks from each CMIP5 model and associated precipitation over North America (Deser et al. 2012) shows significant differences between each model, while the future temperature and moisture changes predicted by each model shows strong commonality. The PGW approach focuses on the thermodynamic changes predicted by global climate models and thus takes advantage of the fact that temperature and moisture changes are relatively robust from model to model.

The approach can be viewed as a way of answering the question: "What would the weather of the current climate look like under a future warmer and moister climate?".

\section{Verification}

The Newman et al. (2015) ensemble of gridded observations were used to verify the model simulations for the current climate. The unique aspect of this ensemble is that it takes into account observational uncertainties. The ensemble was generated by probabilistic interpolation of in situ station observations and includes terrain impacts (e.g., elevation and terrain slope) on the spatial distribution of precipitation and temperature. This dataset is a 100-member ensemble of daily precipitation and temperature on a 1/8-degree grid $(\sim 12 \mathrm{~km})$ and at the time was available for the period 1980-2012 and has since been updated to 1980-2016 (http://dx.doi.org/10. 5065/D6TH8JR2). The comparison between model and gridded ensemble showed that the temperature and precipitation over the western U.S. were within the uncertainty of the ensemble. For further details of the verification of the CONUS simulation see Liu et al. (2017).

The model performance for this study is evaluated by comparing the model snowfall and snowpack in terms of snow water equivalent (SWE) to observed SNOTEL data (Serreze et al. 1999; http://www.wcc.nrcs.usda.gov/snow/). SNOTEL observations provide a long-term record of precipitation from weighing precipitation gauges and snowpack from snow pillows (photos in Fig. 1b) at over 800 sites throughout the western U.S., with 573 sites operating throughout the simulation period 1 October 2000-30 September 2013 (colored dots in Fig. 1b). These sites are owned and operated by the Department of Agriculture Natural Resource Conservation Service (NRCS) and are in mountainous areas at elevations between $\sim 600$ and $3600 \mathrm{~m}$ above mean sea level. Precipitation measurements are given in $2.54 \mathrm{~mm}$ increments. Although this data resolution is insufficient for examining hourly precipitation and snowfall, the measurements provide a valuable observational source for longer term comparisons (daily and longer). The data have been widely used in the past for climatological studies and comparison to model simulations (Mote et al. 2005; Ikeda et al. 2010; Rasmussen et al. 2011, 2014). Model values to compare to SNOTEL data are the inverse-distance weighted average of the four closest grid points from each SNOTEL 
site location. Other interpolation schemes were tested and the results were independent of the method used.

A primary SNOTEL measurement error is the undercatch of snowfall due to wind (Yang et al. 1998; Rasmussen et al. 2012). However, SNOTEL gauges are typically located in forest clearings where the wind speed is typically less than $3 \mathrm{~m} \mathrm{~s}^{-1}$ (Rasmussen et al. 2012). For such wind speeds, a snowfall under-catch of $~ 10$ to $15 \%$ is observed for single Alter shielded gauges (e.g., Yang et al. 1988). In regards to snowpack measurements using snow pillows, Meyer et al. (2012) found that sites at lower elevations of the Interior West and Cascade Mountains were less likely to experience an overestimate of snowpack, while high elevation sites in the Rocky Mountains and Utah, where dry snow is often observed, can be affected by wind drifting. The SNOTEL data used in this study were quality controlled to eliminate obvious cases of wind drift and other artifacts.

\section{Identification of the eight primary mountain ranges and SNOTEL verification}

\subsection{Eight primary mountain ranges and associated locations of SNOTEL sites}

Figure $1 \mathrm{~b}$ identifies the eight major western mountain ranges chosen for detailed analysis in this study. These ranges were chosen because of their prominence in terms of snowpack and water resources as well as by the availability of SNOTEL data and are similar to the ranges chosen for analysis by Mote et al. (2005). The span of elevations, locations, and the number of SNOTEL sites used in each range are given in Fig. $1 b$ and Table 1.

Note that most SNOTELs in the Blue Mountains in eastern Oregon and Washington (i.e., inter-mountain west, Range 3) are located at elevations between 1100 and $2400 \mathrm{~m}$, while gauges in the Pacific Northwest (Range 1) are located between 500 and $2200 \mathrm{~m}$. The SNOTELs in the central
Sierra Nevada (Range 2) are located up to $3000 \mathrm{~m}$ and other ranges further inland have sites at even higher elevations.

\subsection{Verification of the WRF control run for present climate using SNOTEL data}

Figure 2 compares the 13-year average annual precipitation and SWE accumulation at each of the ranges from the WRF retrospective simulation and the SNOTEL gauges averaged over all the SNOTELs in each range. The uncertainty bars indicate the standard deviation of the 13-year annual means of the SNOTEL observations and WRF model simulation. The SNOTEL precipitation maximizes over the Pacific Northwest (an average annual precipitation of $1700 \mathrm{~mm}$ ), while all the other ranges have typically less than half that amount. The annual snowpack maximum in the Pacific Northwest, however, is near $600 \mathrm{~mm}$ consistent with the lower elevations and warmer conditions, causing much of the precipitation in the Pacific Northwest to fall as rainfall that does not accumulate in the snowpack.

The comparison of precipitation from the SNOTEL precipitation gauges (dashed black) and the WRF precipitation (dashed red) is very good, with the mean of all ranges within $10 \%$ of each other with the exception of Range 8 , and the annual standard deviation nearly the same in the model and observations (Table 2). The recent study by Beck et al. (2019) provides an independent evaluation and also shows excellent performance of the model with regards to precipitation.

The comparison between SWE from the SNOTEL snow pillows and WRF model is also very good, but not as good as for precipitation. While the average last day of seasonal snowpack $(\mathrm{SWE}=0 \mathrm{~mm}$ ) from the WRF model well represents the observations (Fig. 2), the model shows a systematic negative bias in peak SWE in all ranges from $-9 \%$ in the best case and $-56 \%$ in the worst case (Table 2). Note that the date of maximum SWE in both the model and observations are well matched except for Region 6 (Utah).

Table 1 Eight primary mountain ranges, number of SNOTEL sites and elevation range used in this study

\begin{tabular}{lllr}
\hline Range ID & Mountain range, state & Number of sites & Elevation range (m) \\
\hline 1 & Pacific Northwest in Washington and Oregon & 81 & $515-2243$ \\
2 & Central Sierra Nevada in California & 25 & $1864-2931$ \\
3 & The Blue Mountains in eastern Oregon and Washington & 24 & $1158-2411$ \\
4 & Mountains in Idaho and eastern Montana & 106 & $939-2902$ \\
5 & Mountains in south-central Montana and western Wyoming & 105 & $1792-3079$ \\
6 & Mountains in Utah & 73 & $1777-3342$ \\
7 & Mountains in Colorado and north-central New Mexico and southern & 105 & $2268-3542$ \\
8 & Wyoming & 19 & $1865-2966$ \\
\hline
\end{tabular}



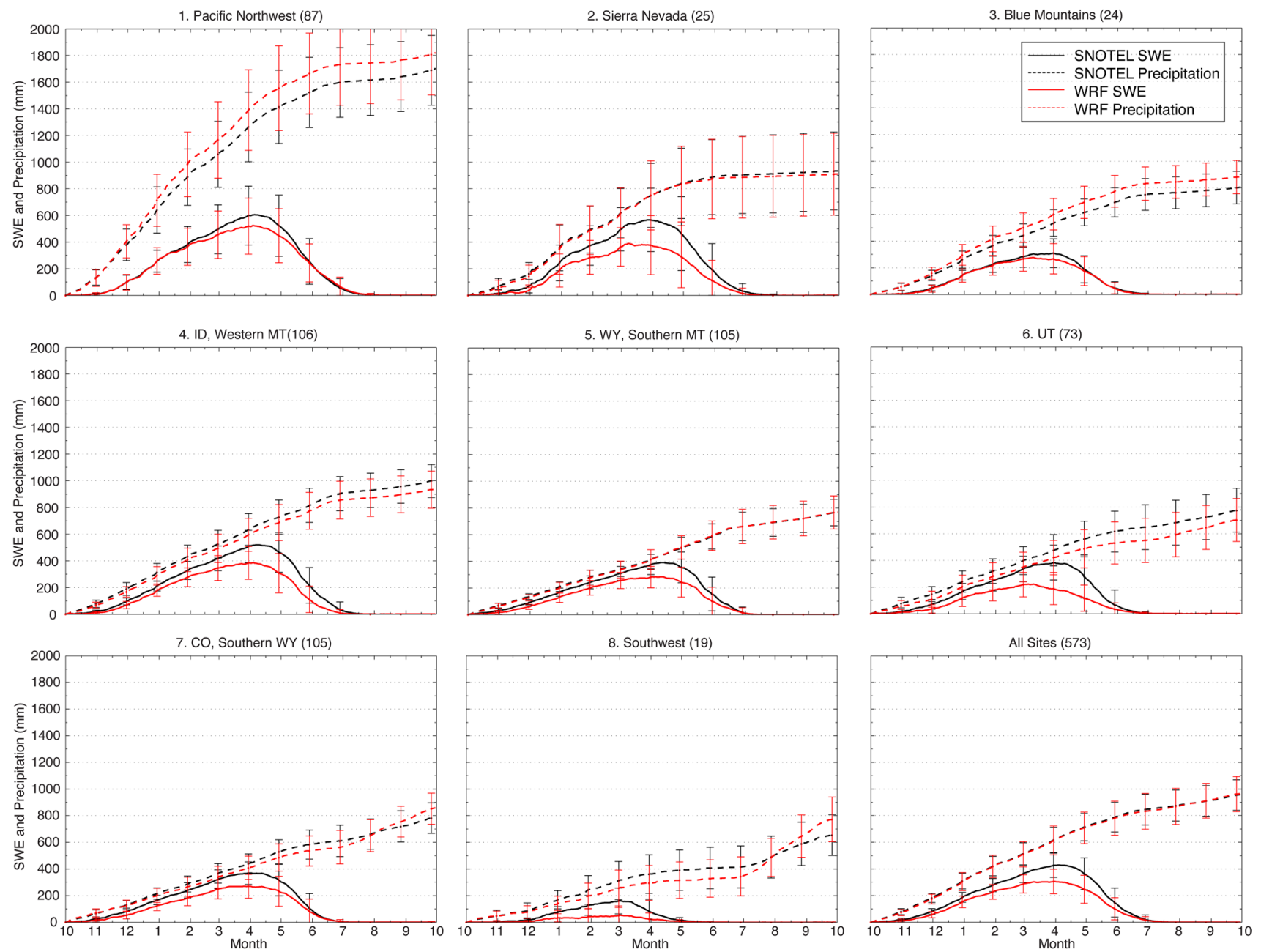

Fig. 2 Time history comparison of precipitation accumulation and annual cycle of SWE from the 13-year mean SNOTEL measurements and WRF current climate simulation averaged over SNOTEL sites in the eight sub-domains shown in Fig. $1 \mathrm{~b}$ and over all SNOTEL sites

in the Western U.S. shown in Fig. 1a. The vertical bars indicate one standard deviation from the 13-year mean. Numbers in parenthesis are the number of SNOTEL sites included in each comparison

Table 2 WRF model root mean squared error and percent bias of 13-year mean annual precipitation and maximum SWE with respect to SNOTEL measurements in each sub-region and all of Western U.S. sites

\begin{tabular}{lrrrrrrrrr}
\hline & Region 1 & Region 2 & Region 3 & Region 4 & Region 5 & Region 6 & Region 7 & Region 8 & All sites \\
\hline Annual precipitation RMSE (mm) & 137.4 & 50.7 & 87.4 & 74.8 & 34.1 & 90.6 & 90.1 & 181.01 & 34.7 \\
Annual precipitation percent bias & 6.9 & -2.6 & 9.7 & -6.8 & -0.05 & -9.4 & 9.0 & 18.8 & 0.6 \\
Peak SWE RMSE (mm) & 77.7 & 184.7 & 42.0 & 127.0 & 98.3 & 190.7 & 103.7 & 113.6 & 121.7 \\
Peak SWE percent bias & -10.8 & -26.3 & -9.1 & -23.1 & -23.4 & -43.4 & -24.8 & -56.3 & -26.2 \\
\hline
\end{tabular}

To understand Region 6 behavior further, SNOTEL sites in Region 6 (Utah), in particular, were reviewed in detail. First of all, we confirmed that the microphysics scheme was producing snow when the SWE and precipitation field in the SNOTEL were also indicating snow as evident by both increasing proportionally.
Second, we examined the snow model in NOAH-MP. For most of the SNOTEL sites in Utah, the model melted/ sublimated snow earlier than the observations, suggesting that the Noah-MP Land Surface Model (LSM) did not correctly handle the snow ablation process. The tendency for the Noah-MP LSM to underestimate SWE due to higher 
snow ablation rates is consistent with the finding in Xiao et al. (2021). They examined the ability of several hydrological models (including Noah-MP LSM) to simulate observed snowpack during the snow ablation period and found that all the models produced snow ablation earlier than the ten SNOTELs sites chosen for their study and that this tendency was more correlated to net radiation in the model than surface temperature. Modeling the snowpack life cycle is challenging for snow models to represent but this analysis provides some hints on possible improvements. We hope to further investigate this behavior in future studies.

Liu et al. (2017) showed that the WRF simulations well capture the spatial distribution of SNOTEL-observed annual and seasonal precipitation (their Fig. 8). Overall, the performance for both precipitation amount and SWE is reasonable for all the ranges (except possibly Utah) and adequate for studying the change in future precipitation and snowpack in future climate, especially considering that any small bias related to the absolute amount of precipitation or SWE will be removed when the results are subtracted from each other. Although the elevation over which the computation is made is limited, these sites were chosen to represent and monitor high-elevation watershed snowpack and thus represents a large mass fraction of snowpack for a given mountain range (https://www.wcc.nrcs.usda.gov/about/mon_automate.html).

\section{Future projected changes of temperature, precipitation, snowfall, rainfall and snowpack over the western U.S.}

\subsection{Temperature and precipitation}

The near surface PGW future temperature over the western U.S. (Fig. 3a) shows a nearly uniform $\sim 4{ }^{\circ} \mathrm{C}$ annual increase over the entire western U.S. for the RCP8.5 scenario, consistent with the CMIP5 model ensemble mean predictions of the same (Liu et al. 2017, their Fig. 14).

The trend in precipitable water (Fig. 3b), shows a large increase of $>40 \%\left(\sim 10 \%{ }^{\circ} \mathrm{C}^{-1}\right)$ in the future climate over the west, significantly more than the $25-35 \%$ predicted by the WRF model in the eastern U.S. and expected by the $7 \%{ }^{\circ} \mathrm{C}^{-1}$ water vapor-to-temperature relationship characterized by the Clausius-Clapyron $(\mathrm{C}-\mathrm{C})$ equation. This result is consistent with the pattern of CMIP5 model monthly mean increase of water vapor pattern over CONUS for the RCP8.5 scenario (Dai et al. 2017). The largest increases of precipitable water in the WRF simulation are observed to occur over the highest terrain, with values up to $50 \%$ over the Sierra Nevada and Rocky Mountains.

Somewhat surprisingly, the future increase in annual precipitation over the western U.S. is on average only 18\% or $\sim 3.9 \%{ }^{\circ} \mathrm{C}^{-1}$ (Fig. $4 \mathrm{~d}$ ), much less than the $40 \%$ increase predicted for precipitable water. The hatching in Fig. $4 \mathrm{~d}$ indicates that this increase is statistically significant at the 5\% significant level from the Student's t-test. Seasonal analysis (Fig. 4) reveals that this increase is primarily from winter storms. Locally, however, this increase can be modulated due to mesoscale and microphysical effects; later sections will describe these effects in detail.

\subsection{Snowfall}

The PGW future projected change in mean snowfall over the western U.S. on an annual basis is for a $\sim 40 \%$ decrease (Fig. 5a). Much of this statistically significant annual decrease occurs in the autumn, winter and spring in regions west of Colorado, Wyoming, Montana and New Mexico (Fig. $5 \mathrm{~d}, \mathrm{f}, \mathrm{h}, \mathrm{j}$ ). This latter region is predicted to have enhanced snowfall in the winter, resulting in significantly less snowfall loss on an annual basis.

During the central three months of winter (DJF, Fig. 5c, g), mean snowfall decreases west of Colorado, Wyoming (a) Near-surface temperature change

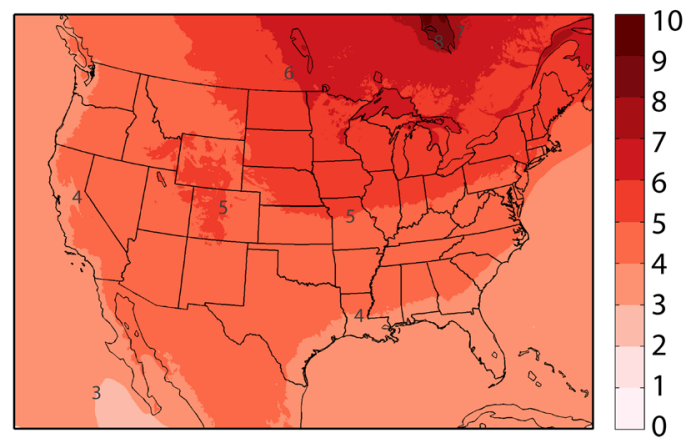

(b) Precipitable water change

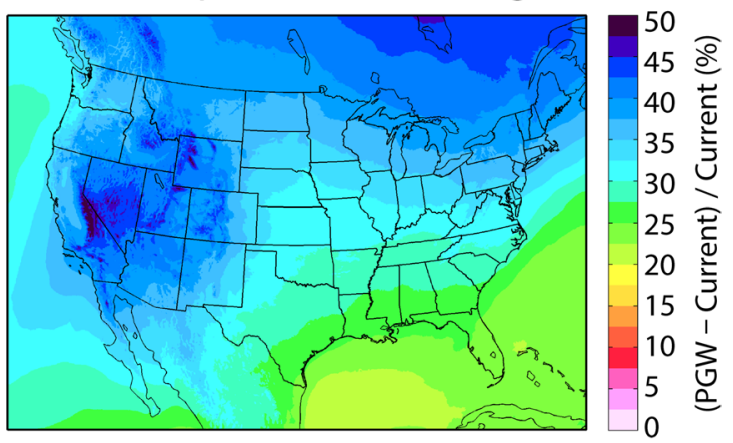

Fig. 3 Change in the 13-year mean a near-surface temperature $\left({ }^{\circ} \mathrm{C}\right)$ and $\mathbf{b}$ column-integrated precipitable water (\%) in the future climate simulation with respect the current climate simulation 

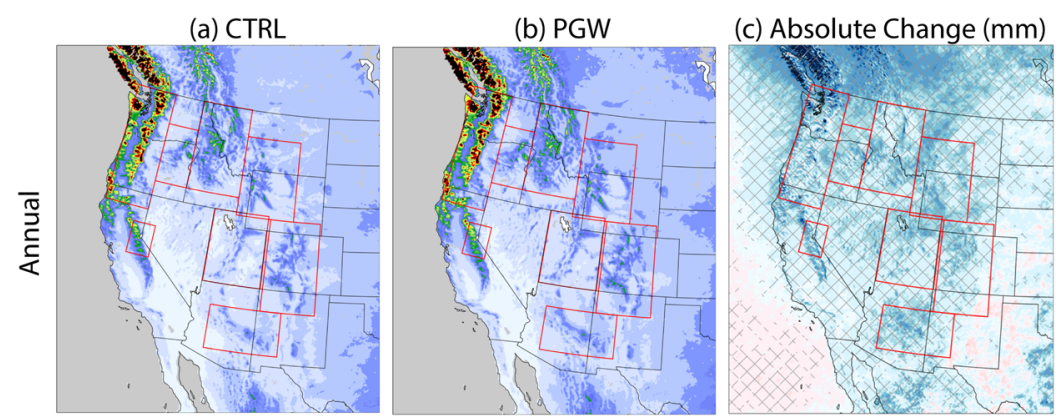

(d) Percent Change

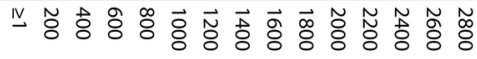
Annual Precipitation $(\mathrm{mm})$

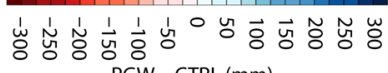
PGW-CTRL (mm)
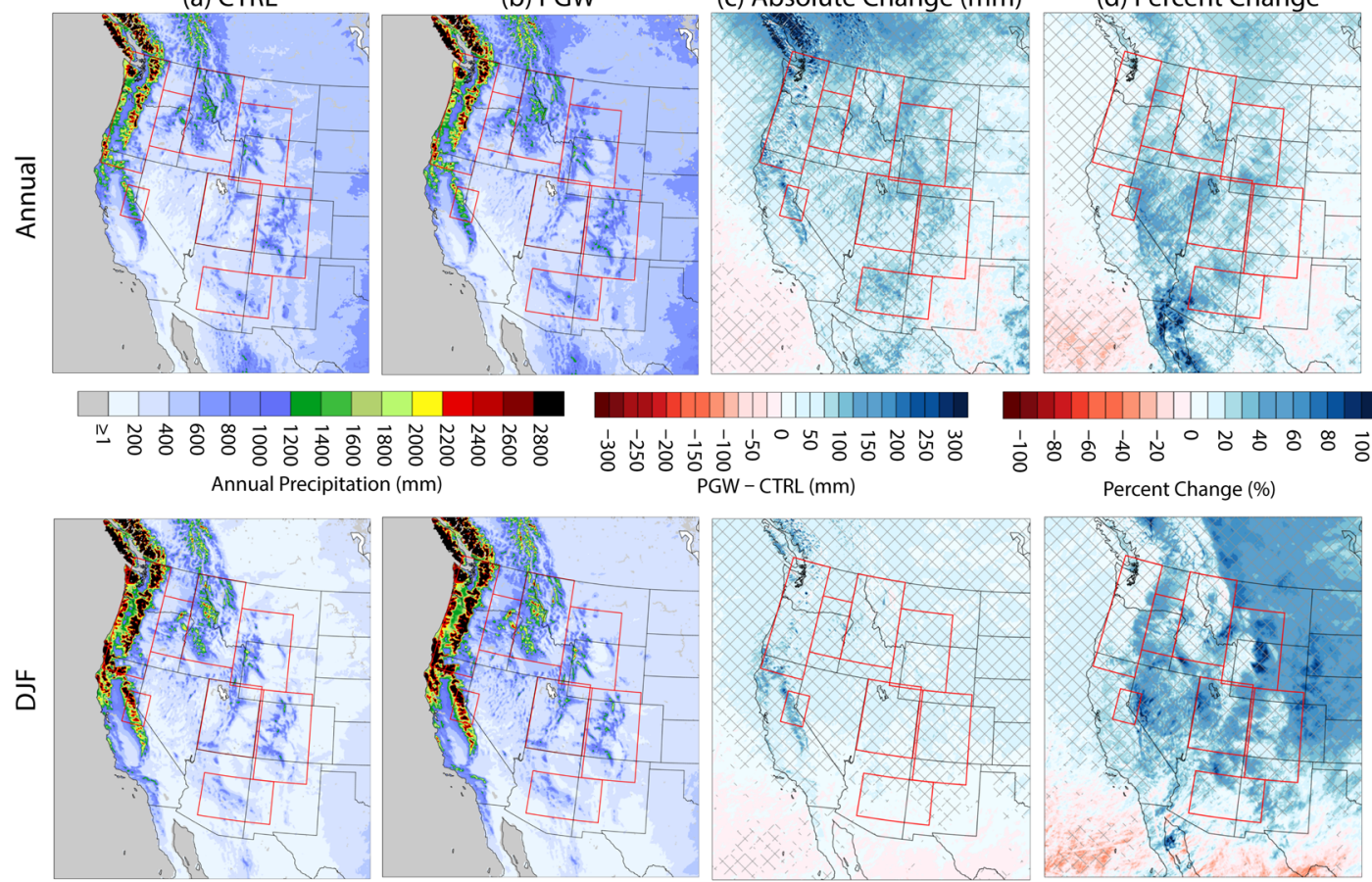

宅 \&
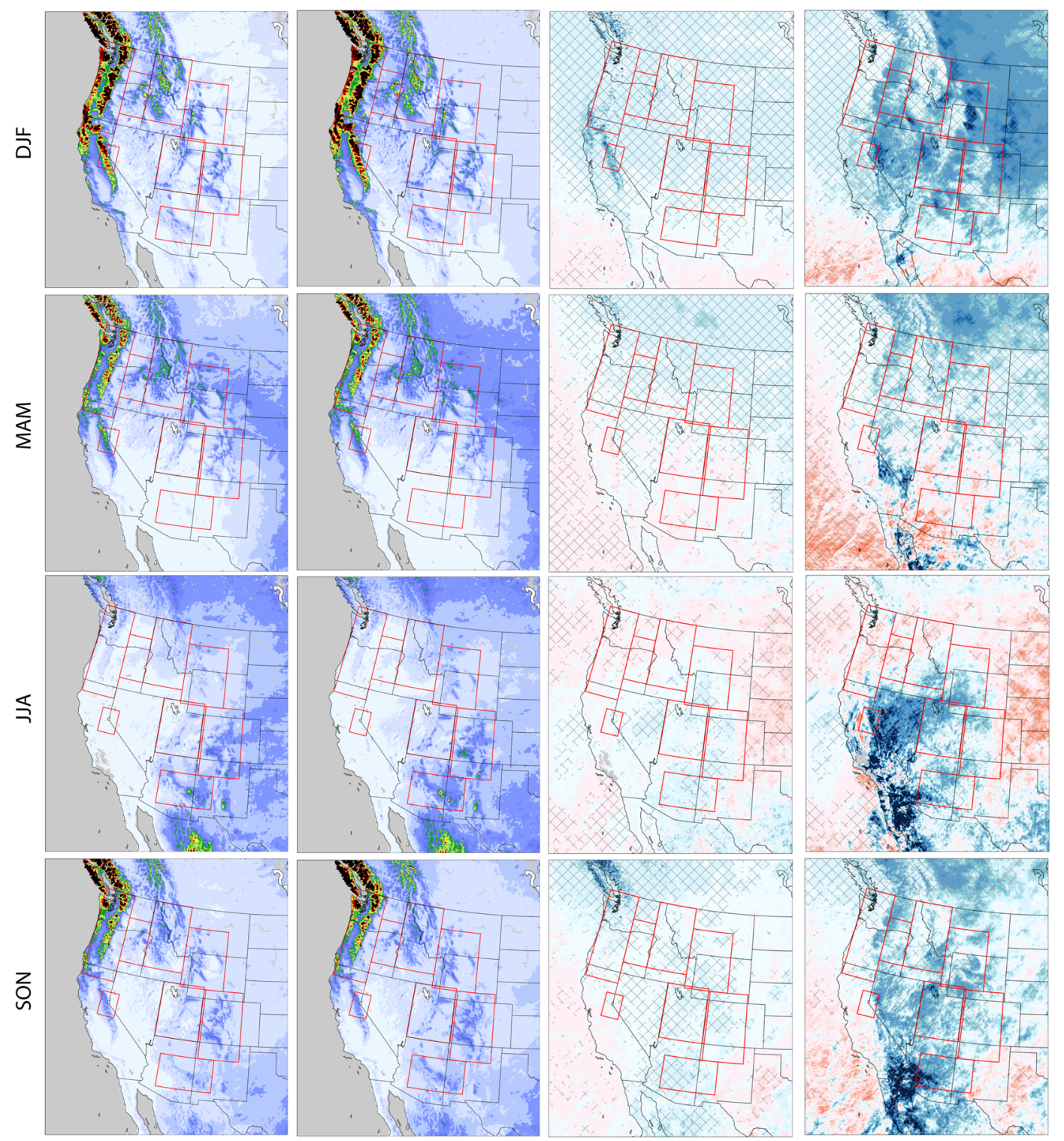

क्षे

है दे
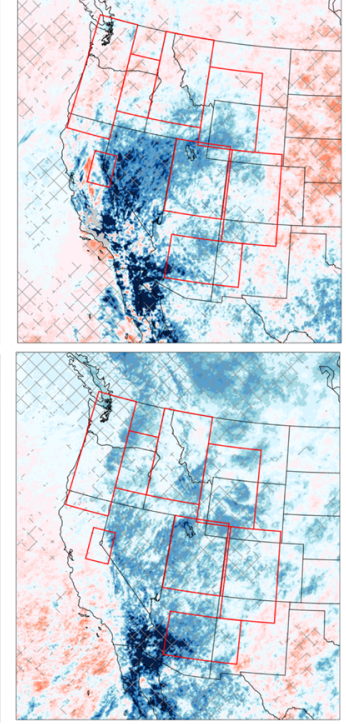

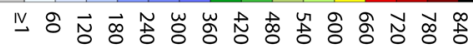
Seasonal Precipitation $(\mathrm{mm})$

$\frac{1}{\circ} \stackrel{1}{\circ}$

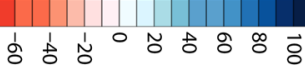

Percent Change (\%) 
4Fig. 4 13-year mean annual and seasonal precipitation from the a current (CTRL) and b future (PGW) climate simulations. 13-year average annual and seasonal $(\mathbf{c})$ change $(\mathrm{mm})$ and $\mathbf{d}$ percent change with respect to the current climate simulation. Hatched areas are the regions where the change signals are statistically significant at a 0.05 significance level. Red rectangles enclose eight sub-regions

and Montana by $\sim 50 \%$ in response to increased conversion of snow to rain associated with temperatures in most of these regions becoming $>0{ }^{\circ} \mathrm{C}$ (e.g., in coastal region and at lower elevation), while snowfall increases by $\sim 11 \%$ in the intermountain west from Colorado northward due to the relatively colder conditions at those locations during mid-winter, including the colder conditions present in the inter-mountain west mountain ranges due to their relatively high elevations.

The decrease in snowfall west of Colorado, Wyoming and Montana is statistically significant, while the increase is statistically significant over Colorado, Wyoming and the Canadian Rockies and Saskatchewan, consistent with increased moisture and cold conditions in this region even for a $4{ }^{\circ} \mathrm{C}$ warmer climate.

\subsection{Rainfall}

The projected future mean annual rainfall (Fig. 6) shows an overall increase of $\sim 130 \%$ over much of the west, with statistically significant increases of $>100 \%$ over the Cascade Mountains in Washington and Oregon and as high as $~ 300 \%$ in the Sierra Nevada Mountains in California. Most of this increase occurs during the winter and spring and in the precipitation shadow regions (Fig. 6c, d, g, h).

These results indicate that one of the primary impacts of climate change in the west as depicted by the PGW approach with the RCP 8.5 scenario is the conversion of snowfall to rainfall over major mountain ranges near the Pacific Ocean. In these regions the average monthly winter temperature is close to $0{ }^{\circ} \mathrm{C}$ prior to climate warming and thus any future warming will convert much of the precipitation that was snowfall into rain.

\subsection{SWE}

The conversion of snowfall to rainfall and the higher temperatures in a future climate will impact the formation of snowpack. Figure 7 shows the projected change in the 1st April snowpack over the western U.S. using the PGW approach. The general features show large decreases between 40 and $100 \%$ with an average of $\sim 80 \%$. The largest decreases are at lower elevations over the coastal mountain ranges. The reduction is smaller over the mountain ranges in the intermountain west $(<50 \%)$. The smallest changes are found over high peaks of the mountain ranges in Colorado and Wyoming $(<20 \%$ reduction). Since the projected change in SWE subtracts the future SWE from current SWE, any small biases should be removed. However, the absolute bias in Region 6 (Utah) is fairly large (Table 2), so application of the current results to Utah should take this caveat into account.

\section{Future projected changes of precipitation, snowfall, snowpack and temperature over the eight western U.S. major mountain ranges}

Figure 8 presents the snowpack and precipitation time series from the eight mountain ranges averaged over all SNOTEL sites in each respective range (Fig. 1b) for the current and future simulations. The absolute SWE amounts for the historical simulations compare well to the observed SWE except for Region 6 (Utah). Thus, reliance on results from this region show take this caveat into account.

The future precipitation is projected to increase by $\sim 10 \%$ at all the ranges, except for Range 1, as shown by the two dashed curves (black for current and red for future) and Table 3a.

The Pacific Northwest Range (Range 1) is notable for having at least double the annual precipitation compared to the other seven ranges. However, it does not have double the snowpack (indicated by the solid lines, black for current and red for future). The current climate snowpack in the Pacific Northwest Range is less than $60 \%$ of the precipitation by April 1st (the end of typical snow accumulation period), indicating that a large fraction of the precipitation from October to April is rain or that significant melting of the accumulated snowfall has taken place at elevations where SNOTEL sites are located. This is also true to a lesser degree for the Sierra Nevada (Range 2), Blue Mountains (Range 3 ), and Idaho (Range 4). Due to the lower elevations and location closer to the Pacific Ocean, the coastal mountains and Idaho are warmer than the inter-mountain west and thus have a larger fraction of rain and snowmelt (Fig. 8; see also seasonal temperature in each range from Table $3 b$ ).

In contrast, the snowpack in the current climate from Montana, Wyoming, and Colorado ranges (Ranges 5 and 7 ) is just slightly less than precipitation in that region until it reaches the maximum in SWE, after which the SWE decreases with respect to the precipitation, indicating that most of the falling precipitation is snow and remains in the snowpack. This is a result of very little of the precipitation taking the form of rain and the average temperatures being $<0{ }^{\circ} \mathrm{C}$ (Table 3b, Fig. 8).

In the future, as a result of warming being more or less geographically uniform (Fig. 3a), more rain is expected to occur in the coastal mountain ranges because they start out warmer, leading to less snowpack. For instance, the Pacific 


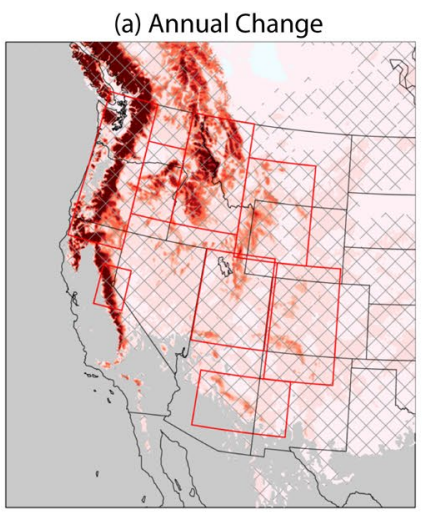

(c) DJF Change

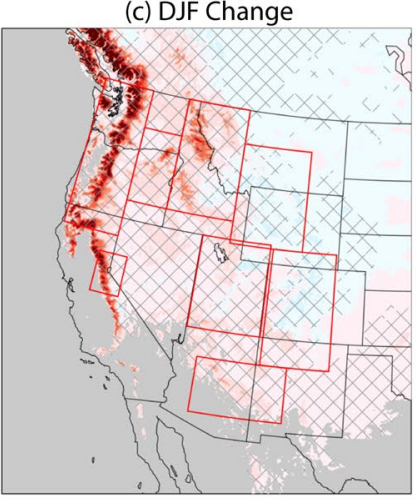

(g) DJF Percent Change

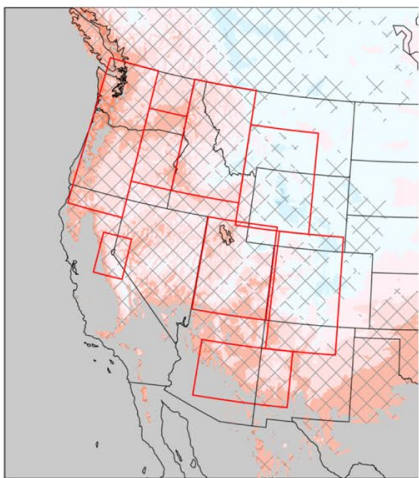

Fig. 5 13-year mean annual a change ( $\mathrm{mm}$ ) and $\mathbf{b}$ percent change in snowfall with respect to the current climate simulation. 13-year mean seasonal snowfall change (mm) for $\mathbf{c}$ DJF, d MAM, e JJA, and f SON.

Northwest, Sierra Nevada, Blue Mountains, and Idaho (ranges 1-4) all show between 45 and $70 \%$ reduction in the maximum snowpack by the late 21 st Century (Fig. 8). The most extreme reduction is in the Pacific Northwest where a reduction in peak snowpack of $70 \%$ is predicted. In contrast, the inter-mountain west ranges (ranges 5-7) show only $23-40 \%$ reduction in the peak snowpack, except at the Southwest (range 8) where the current climate snowpack is already very small and the peak snowpack decreases by $65 \%$ in the future simulation.

In inter-mountain west ranges the snowpack accumulation curve (red solid line) follow close to the current snowpack

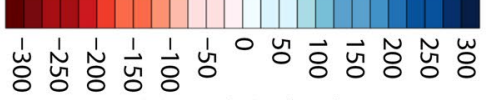 PGW - CTRL (mm)}

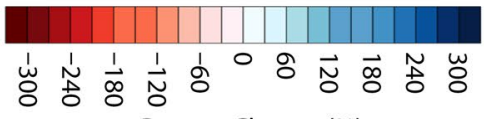 \\ Percent Change (\%)}

(e) JJA Change

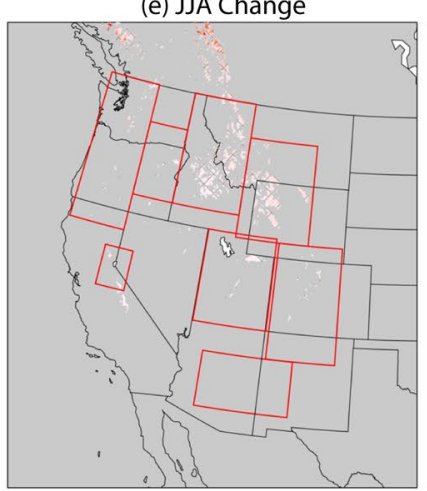

(i) JJA Percent Change

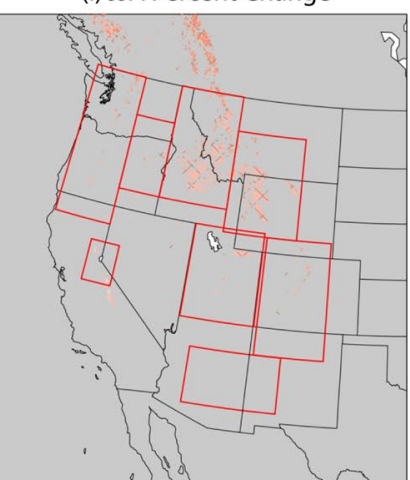

(f) SON Change

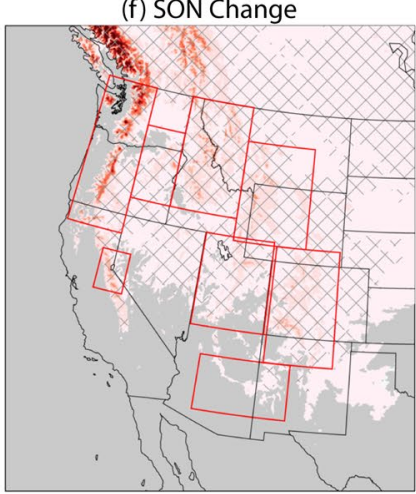

(j) SON Percent Change

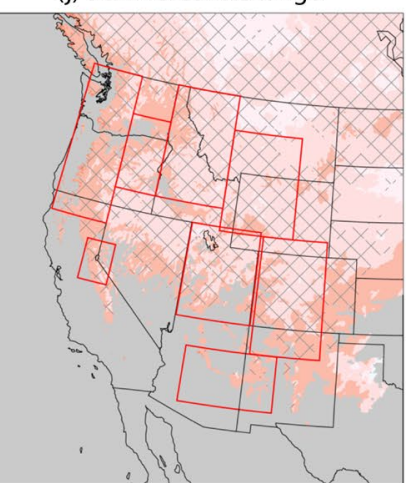

$\mathbf{g}-\mathbf{j}$ are the same as $\mathbf{c}-\mathbf{f}$ but showing percent change. Areas of statistically significant change are indicated by hatches

accumulation curve (black solid line) until it reaches the maximum, indicating that the future temperature in these ranges stays mostly $<0{ }^{\circ} \mathrm{C}$ (Table $3 \mathrm{~b}$, Fig. 8) during this time period. In all ranges, the future climate peak snowpack dates are earlier than the current climate by 20-30 days.

After April 1st more significant impacts of a warming climate are noted likely due to the combined effects of the spring temperatures being closer to $0{ }^{\circ} \mathrm{C}$ and the presence of a snow albedo feedback during this period (Minder et al. 2016). Figure 10 further reveals that snowpack melts completely in the future spring about one month earlier than the current spring in the PGW future climate simulation. 


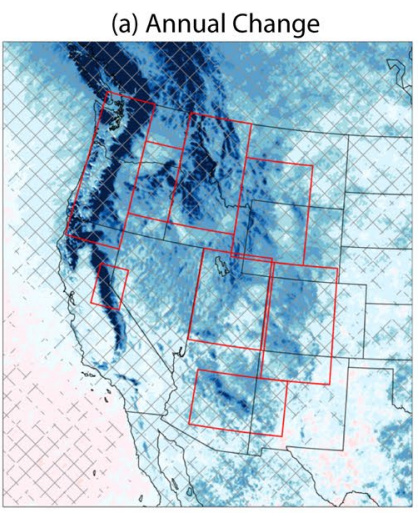

(c) DJF Change

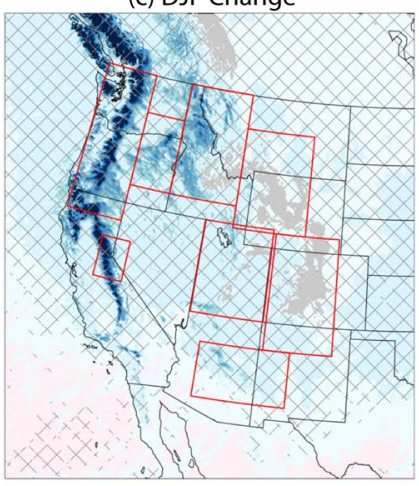

(g) DJF Percent Change

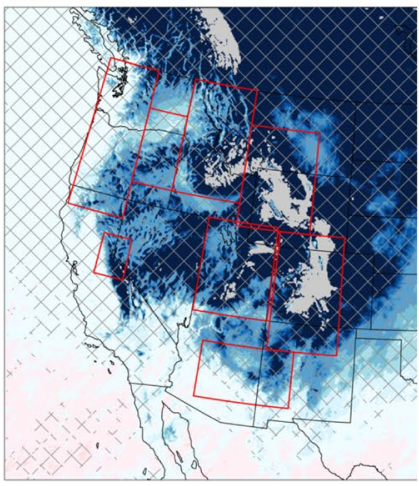

(b) Annual Percent Change

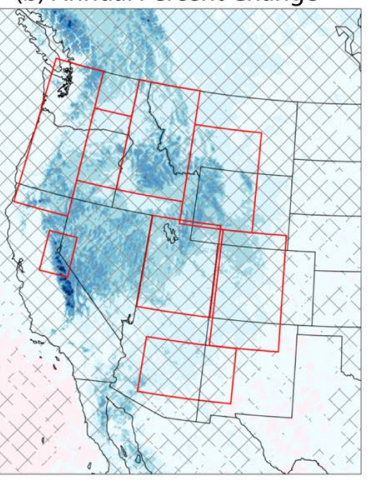

(d) MAM Change

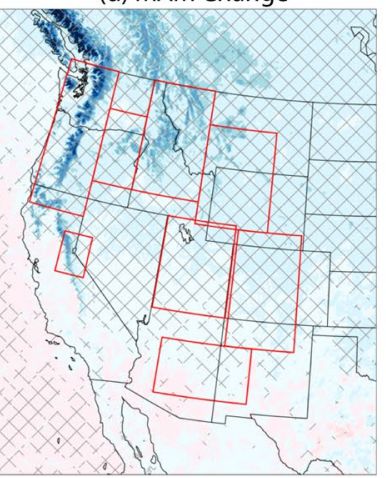

(h) MAM Percent Change

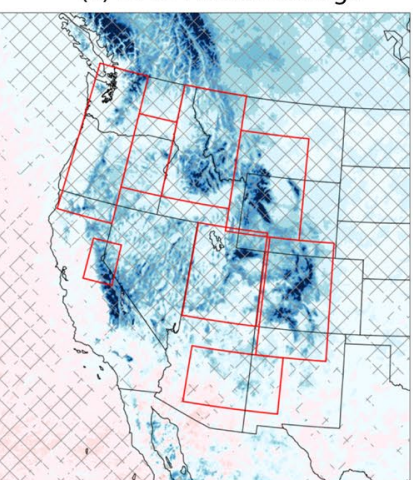

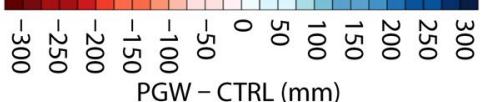

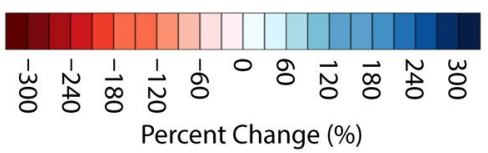

(e) JJA Change

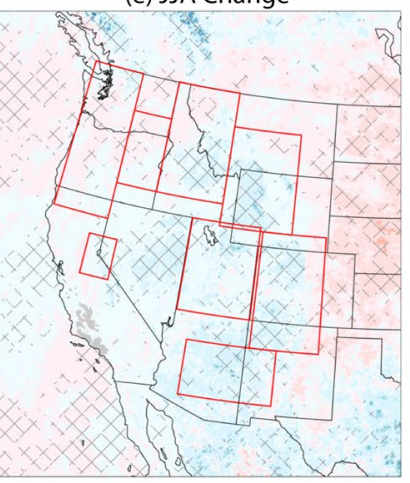

(i) JJA Percent Change

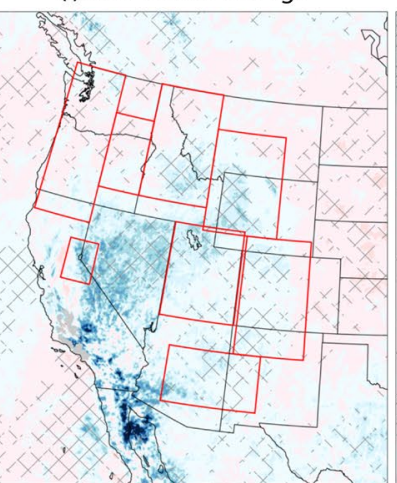

(f) SON Change

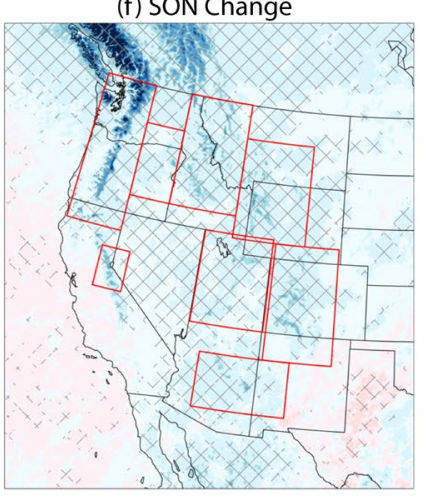

(j) SON Percent Change

Fig. 6 Same as Fig. 5 but for rainfall

\section{Seasonal changes in the current and future snowfall and snowpack across the mountain ranges of the western \\ U.S.}

Analysis of the seasonal changes of current and future snowfall and snowpack across the mountain ranges of the western U.S. are examined by comparing the annual cycle of precipitation, rainfall, snowfall, and 2-m temperature at SNOTEL sites in the eight mountain ranges (Figs. 9, 10).

Precipitation
Precipitation is noted to maximize in the ranges on the Pacific coast (ranges 1-2) predominantly in the winter months associated with Pacific storm occurrences at that time (Fig. 9a, b). In contrast, precipitation accumulates nearly uniformly across the year in the interior and continental mountain ranges of the western U.S (e.g., Fig. 9c).

Future changes in precipitation reflect these patterns as well, with more precipitation in the winter months for the ranges along the mountains along the Pacific coast, and more uniformly across the year for the intermountain west (Fig. 9). There is a net positive change in the annual future precipitation over all ranges at SNOTEL sites. 
Fig. 7 a Absolute change and $\mathbf{b}$ percent change of the 1st April snowpack (SWE) associated with the PGW approach using the RCP8.5 scenario

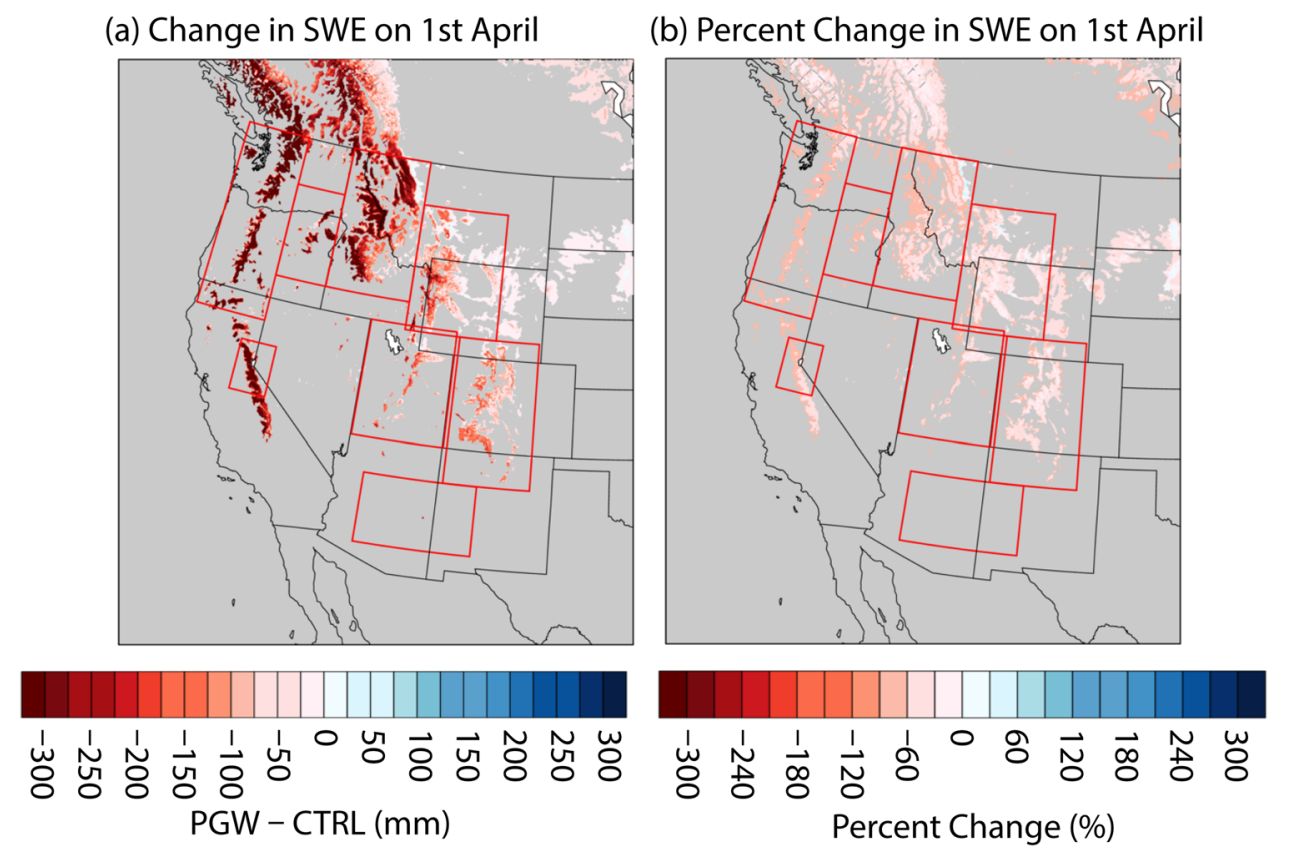

\subsection{Snowfall}

Snowfall occurs at all the mountain ranges from October to May, with a maximum in December for the Pacific coastal ranges but not the intermountain west-a similar trend to the precipitation annual cycle (Fig. 9d, f). Snowfall decreases over all ranges with the larger negative change for the Pacific coastal ranges and weaker negative change for the intermountain west in the future climate (Fig. 9).

\subsection{Rainfall}

Rainfall largely reflects the precipitation seasonal pattern in the Pacific coastal ranges, with a maximum in the winter months (Fig. 9g, h), while the inter-mountain ranges rainfall maximizes in the spring (range 4-5) and summer (ranges 6-8) with nearly no rainfall in the winter (e.g., Fig. 9f).

For all ranges, there is a net positive change in the future annual rainfall. Rainfall in the future climate simulation increases in the Pacific coastal ranges in winter and spring, with a maximum increase in the winter. The rainfall in the inter-mountain west increases throughout the winter and spring.

\subsection{2-m Temperature}

The above behaviors can largely be explained by comparing the time series of $2-\mathrm{m}$ temperature at the various ranges (e.g., Fig. 10). The 2-m temperature in the coastal ranges is close to $0{ }^{\circ} \mathrm{C}$ in the current climate during the winter when precipitation is maximum, but $2-4{ }^{\circ} \mathrm{C}$ higher in the future climate. As noted earlier, this higher temperature results in a larger fraction of snowfall converting to rain in the winter, and more rapid melting of snowpack in the future climate. In contrast, the temperature in the inter-mountain west (e.g., Colorado shown in Fig. 10c) is $2-5{ }^{\circ} \mathrm{C}$ below $0{ }^{\circ} \mathrm{C}$ in the winter time, and only moves above $0{ }^{\circ} \mathrm{C}$ in the early spring in the current climate simulation. The future $2-\mathrm{m}$ temperature in these inter-mountain west ranges increases to $\sim 0{ }^{\circ} \mathrm{C}$ during the winter, and thus their overall climate becomes similar to the present-day climate of the Pacific coastal ranges. This means that most of the snow does not melt to rain, and that snowpack melt starts a month earlier in the spring, as mentioned earlier, when the ambient temperature moves above $0{ }^{\circ} \mathrm{C}$ and snow albedo feedbacks are strong (Minder et al. 2016). As a result, there is a relatively smaller reduction in the peak snowpack in the inter-mountain west in the future simulations while in the Pacific coastal ranges the snowpack is reduced by up to $70 \%$ depending on the range.

Although the Sierra Nevada Range (range 2) is located further south of the Pacific Northwest (range 2), its snowpack is only decreased by $~ 45 \%$ compared to the Pacific Northwest (range 1) peak snowpack decrease of $\sim 70 \%$. This likely occurs because the higher elevations of the Sierra Nevada range (up to $3000 \mathrm{~m}$ ) compared to the Pacific Northwest mountain range $(\sim 2000 \mathrm{~m})$ and the associated lower temperatures for these mountains maintaining more snowpack than in Range 1. In the future climate, the temperatures 
Fig. 8 Time series of 13-year mean precipitation accumulation and SWE averaged over all SNOTEL site locations in each sub-region indicated from CTRL and PGW simulations. Vertical bars indicate \pm one standard deviation from the 13-year mean, showing the year-to-year variation. Note that all SNOTEL site locations were included in the dataset here (as opposed to sites with the complete measurements in the simulation period)

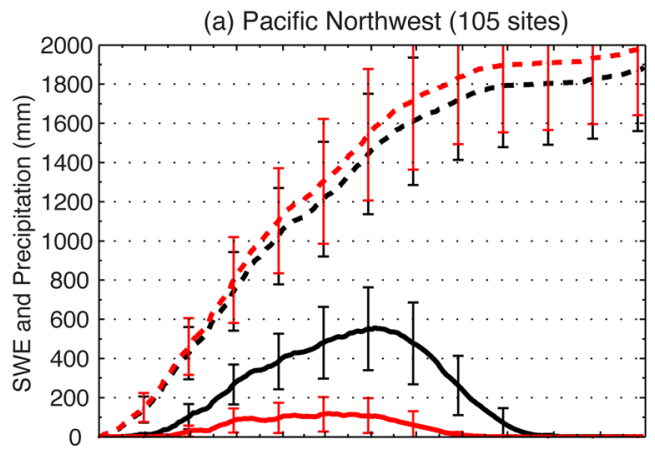

(c) Blue Mountains (28 sites)

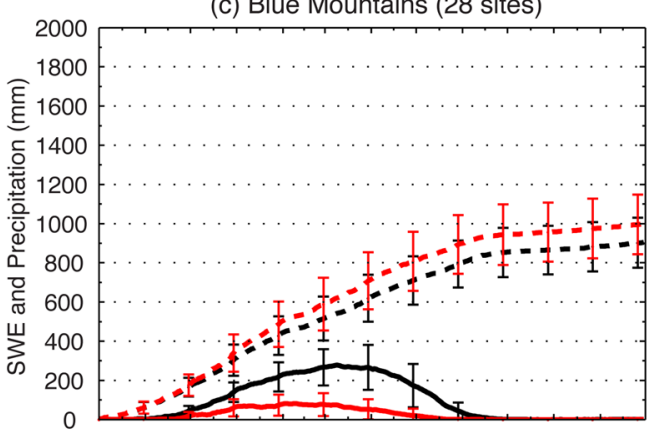

(e) Wyoming and S. Montana (121 sites)

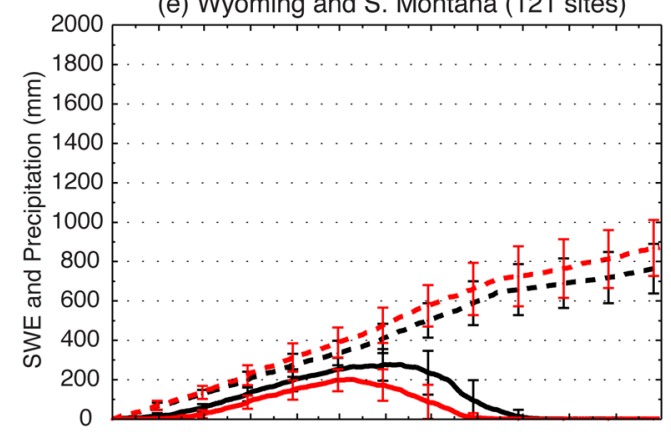

(g) Colorado and Southern Wyoming (144 sites)

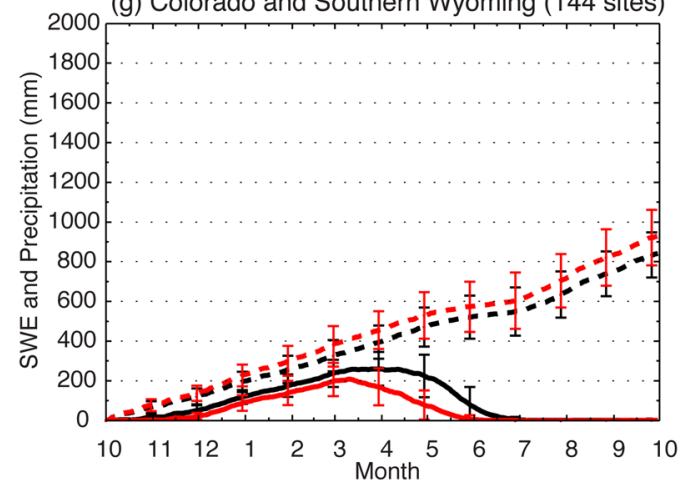

(b) Sierra Nevada (31 sites)

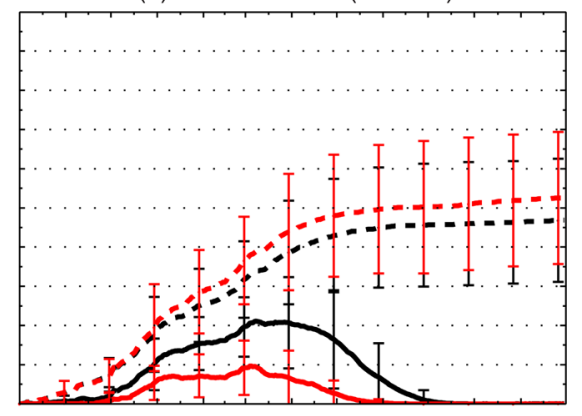

(d) Idaho and Western Montana (110 sites)

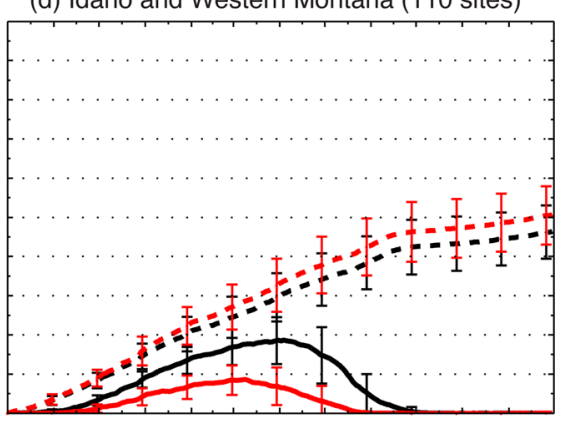

(f) Utah (95 sites)

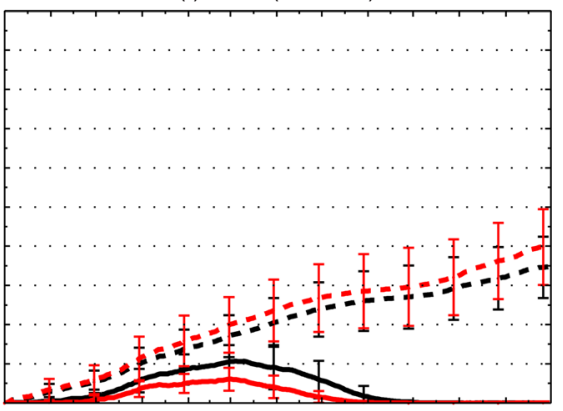

(h) Southwest (25 sites)

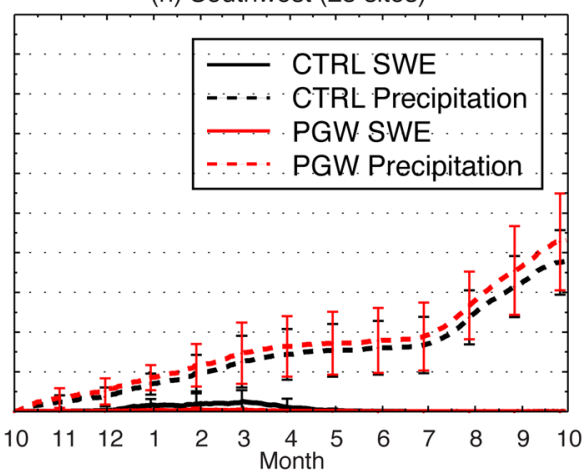

are $3-4{ }^{\circ} \mathrm{C}$ higher in both ranges, leading to more melting in the Pacific Northwest than the Sierra Nevada. A second possible factor is that the Pacific Northwest increase in rainfall is over $100 \mathrm{~mm}$ more than the Sierra Nevada's (Pacific Northwest rainfall accumulation is $300 \mathrm{~mm}$ while Sierra Nevada accumulation is $200 \mathrm{~mm}$ ), causing more rainon-snow melting in the Pacific Northwest than the Sierra Nevada (Musselman et al. 2018).

\section{Mesoscale and microphysical dependence of climate change over the Pacific coastal mountain ranges}

In contrast to the inter-mountain west ranges, maximum precipitation does not form at the highest elevations in the Pacific coastal ranges but along the slopes of the upstream region of the barrier about $2 / 3$ of the way up its slope. This 
Table 3 (a) Future percent change in annual precipitation at SNOTEL sites in each sub-region associated with Fig. 1b. (b) 13-year average seasonal mean 2-m temperature and the April 1st 2-m temperature $\left({ }^{\circ} \mathrm{C}\right)$ from the current $(\mathrm{CTRL})$ and future (PGW) climate simulations in corresponding sub-regions

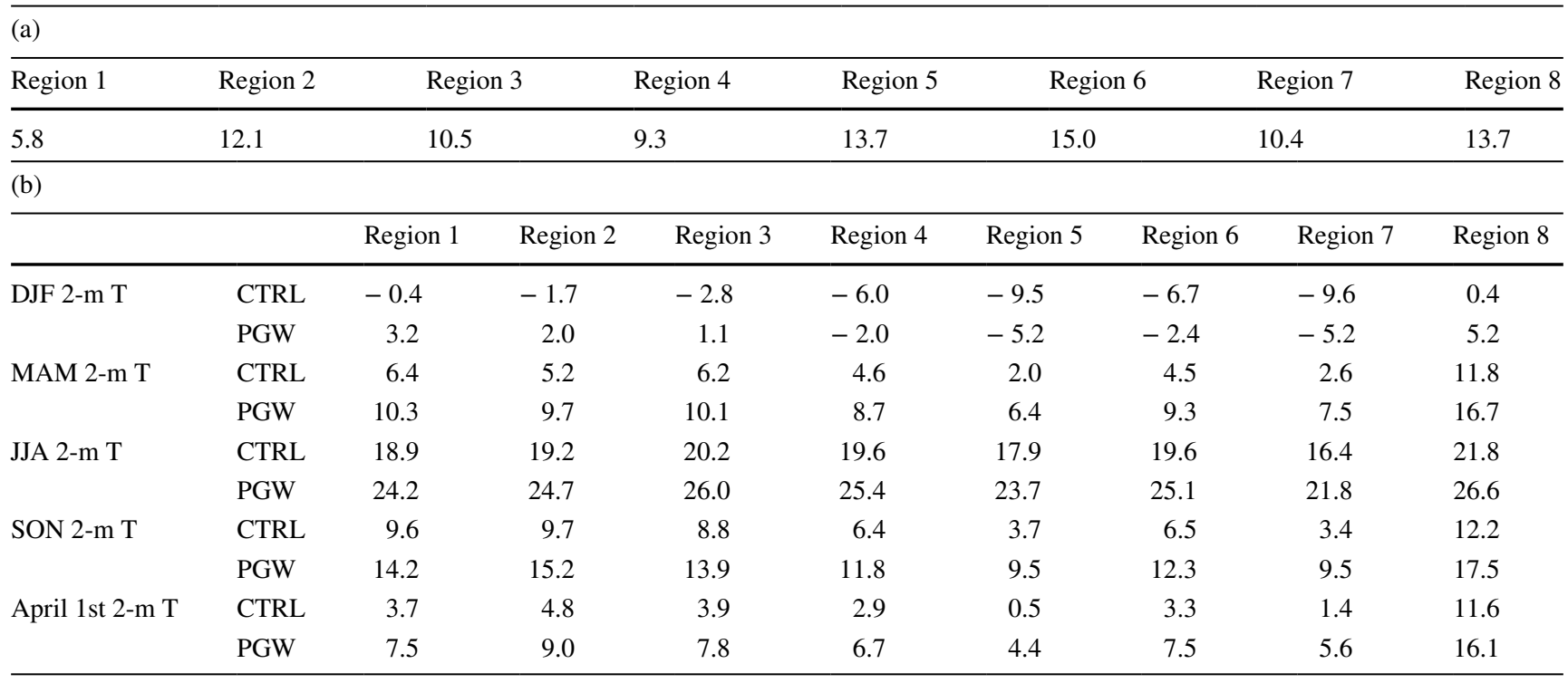

is due to the strong blocking of the flow by the relatively tall Cascade and Sierra Nevada mountains, preventing the low-level moisture laden air from the Pacific from flowing over the barrier. The blocking process results in a southerly barrier jet forming during precipitation events in both the Sierra Nevada range in California (range 2) and in the Cascade ranges of the Pacific Northwest (range 1) (Rasmussen et al. 1988; Garvert et al. 2005a, b; Hughes et al, 2012).

The dominance of this barrier jet during precipitation is evident in our results for both range 1 and 2 (Fig. 11a, b). The spatial distribution of total surface precipitation for the two ranges in Fig. 11c, d show that the precipitation maximizes about $2 / 3$ of the way up the upstream side of the mountain and not at the mountain top. This is due to the barrier jet being confined to the mid-levels of the barrier in both ranges. This is shown for the Sierra Nevada in Figs. 12 and 13 along the southern $\left(A-A^{\prime}\right)$ and northern $\left(B-B^{\prime}\right)$ vertical cross-sections, respectively, marked in Fig. 11d. In particular, the bottom two panels in Figs. 12 and 13 clearly show that the maximum flux of water vapor transported northward is by the barrier jet at these two locations.

The dominant process leading to the precipitation and snowpack distribution in the current climate is the updraft and downdrafts formed as the barrier jet flows over the ridges and valleys associated with the river valleys on the western side to the barrier (Rasmussen et al. 1988; Garvert et al. 2005a, b). This can be clearly seen in the northwest to southeast cross-section of precipitation $\left(\mathrm{C}-\mathrm{C}^{\prime}\right.$ in Fig. 11d; Fig. 14) taken parallel to the barrier jet in the Sierra Nevada's (range 2). Each ridge and valley produce an increase/decrease in snowfall associated with the updraft/downdraft couplet. This process was documented by Garvert et al. (2005a, b) using aircraft and radar data from the recent IMPROVE II field program over the Oregon Cascades and simulated by high resolution model simulations by Rasmussen et al. (1988).

This fundamental precipitation process needs to be captured in order to accurately simulate climate change impacts on precipitation over these important ranges. Two main factors are important: (1) the blocking of the flow by the higher mountains, (2) the local precipitation process created by the local updrafts/downdrafts over ridges/valleys. These two factors lead to the maximum precipitation to occur significantly below the peak of the range. Thus, precipitation processes start at higher temperatures than may be expected from, say, coarse resolution climate models that do not capture either the blocking effect of the flow as a result of the lower mountains modeled nor the local production of precipitation from the local ridges and valleys encountered by the barrier jet.

The future climate PGW model results do not significantly change the storm scale flow. Thus, the main climate change effect in the PGW simulation in this region is an increase in moisture and temperature. The increase in moisture results in a larger flux of moisture along the upstream side of the barrier (bottom panels in Figs. 12, 13), and the increase in temperature leads to a higher melting level and as a consequence more rain than snow. The main impact of the increased moisture flux in the southerly barrier jet is to increase the precipitation over each ridge/valley couplet encountered by the jet (Fig. 14). The relative increase over each ridge/valley couplet is summed over the range to obtain the net climate change impact of the range. For the Sierra 

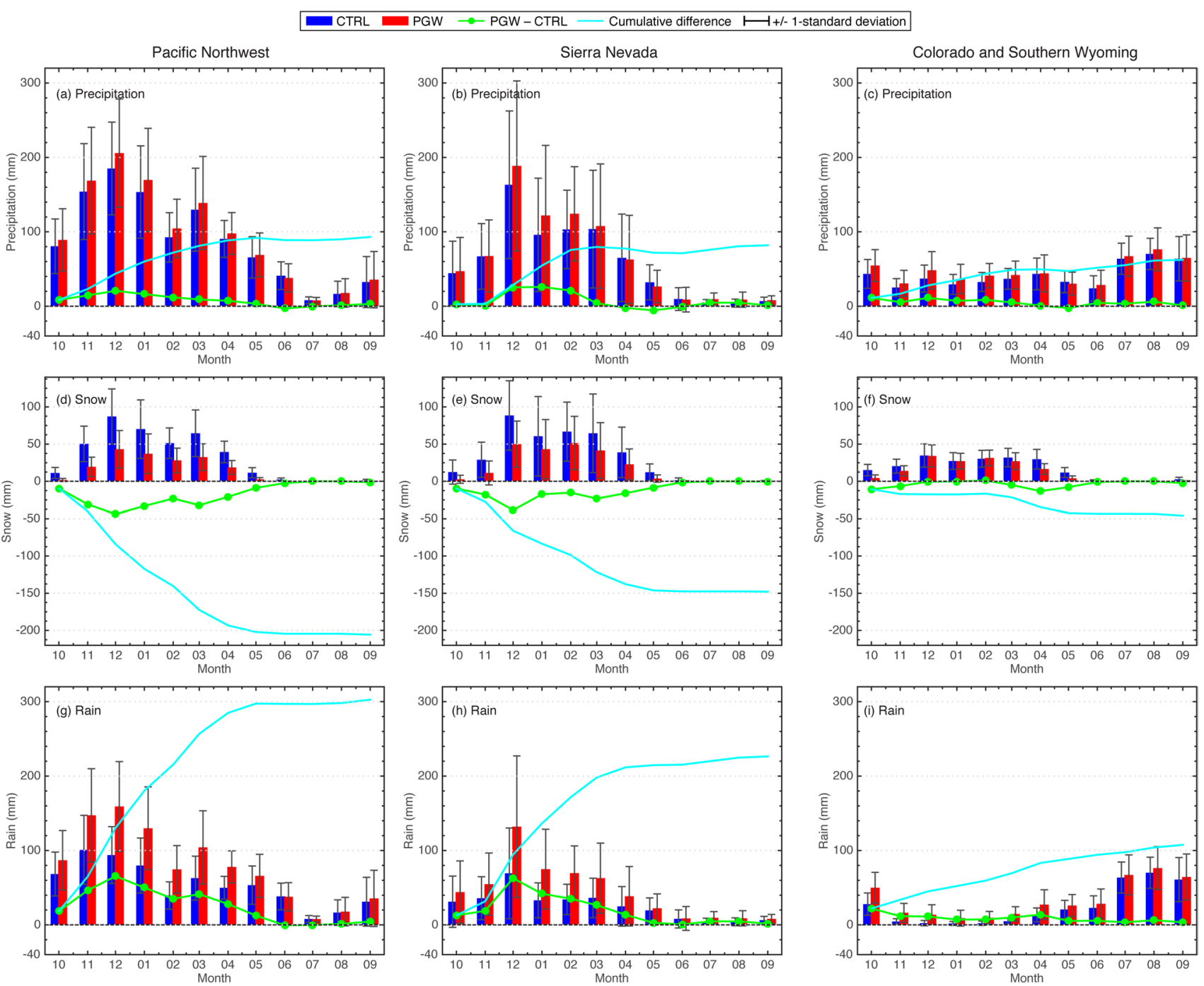

Fig. 9: 13-year mean annual cycle averaged over all model grid points in Pacific Northwest (Range 1, left column), Sierra Nevada (Range 2, center column), and Colorado/Southern Wyoming (Range 7, right column) of a-c precipitation, $\mathbf{d}-\mathbf{f}$ snow, and $\mathbf{g}-\mathbf{i}$ rain. Bars indicate average monthly amount from current (CTRL, blue bars) and future climate (PGW, red) simulations. Error bars indicate \pm one

Nevada and Cascade ranges (ranges 2 and 1), this is 5-8\% $\mathrm{C}^{-1}$ for DJF.

Note that the location of the maximum precipitation along the slope does not change much, but that the fraction of rain is significantly increased due to the higher temperatures. While this is expected, the amount of increased rainfall is not solely due to melting of enhanced amounts of snow, as the snow mixing ratio change does not equal the rain mixing ratio change over the barrier (Figs. 12, 13). Rather, the enhanced moisture flow enhances the cloud water content over each ridge/valley $\left(\mathrm{Q}_{\mathrm{c}}\right.$ panels in Figs. 12, 13), leading to efficient growth of the rain drops as they fall through this region. The growth is enhanced in the future climate due standard deviation associated with the 13-year mean representing the year-to-year variation. Cyan solid lines are the accumulated difference between future and current climate. Green lines with solid circles are the monthly mean difference between the two climate simulations

to the deeper cloud water region. This is reflected in the enhanced precipitation shown in the current and future precipitation amounts along the cross sections in Fig. 15.

\section{Comparison to previous studies}

While specific mountain ranges in the western U.S. have been studied at high resolution (Hughes et al. 2012; Sun et al. 2015), and in aggregate (Chenglai et al. 2018, for example), the current study represents one of the first attempts to examine impacts of climate change on snowfall 


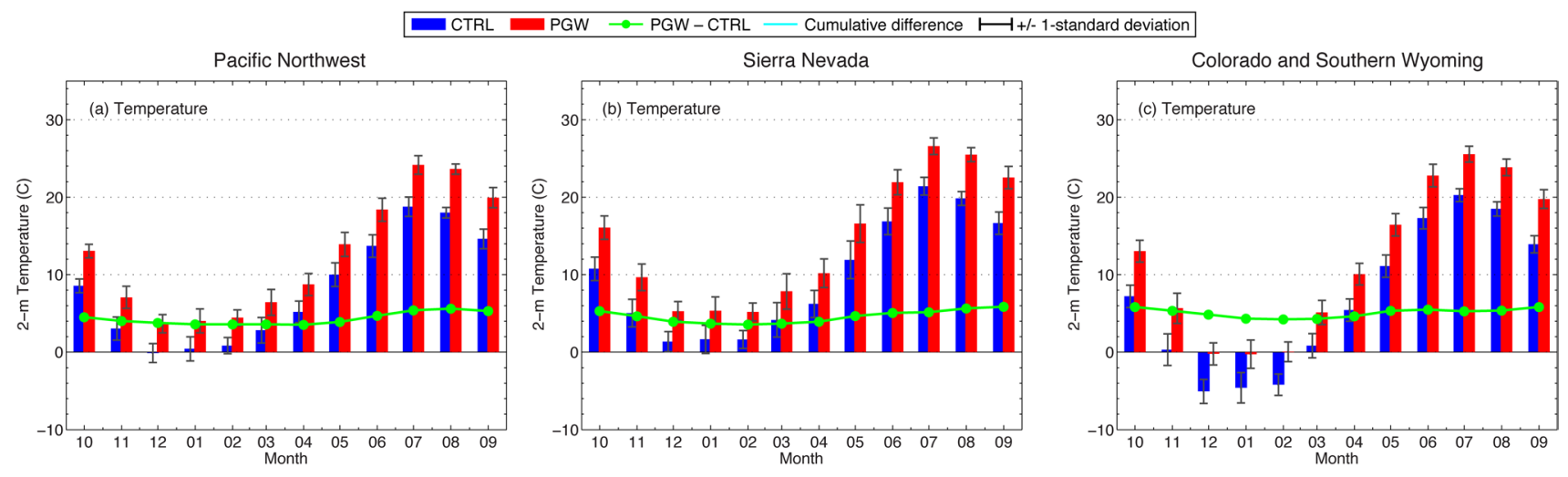

Fig. 10 Same as Fig. 9, but for average 2-m temperature

and snowpack across all the mountain ranges of the western U.S. with a fine model grid spacing of $4 \mathrm{~km}$.

While the number of high resolution modeling studies over the western U.S. have been few, there have been a fair number of Global and Regional Modeling studies conducted for this region and it is of interest to compare the current results to these coarser resolution studies (e.g., Pavelsky et al 2011, 2012; Kapnick and Hall 2012; Hughes et al. 2012; Salzman and Mearns 2012; McCrary et al. 2017; Rhoades et al. 2017; Chenglai et al. 2018). As noted by Rhoades et al. (2017), these previous studies have shown that under global climate change projections for the coming century, temperatures will rise, snowpack totals will decline and higher precipitation-to-snowfall ratios will occur. While our high-resolution simulation predicts the same trends, the details vary. In the following, we compare our high resolution WRF simulations using the PGW approach to the Rhoades et al. (2017, hereafter RUZ) variable resolution simulation. We chose this study to compare with as it examines the RCP8.5 future scenario out to 2100 as in the current study.

RUZ deployed a $28-\mathrm{km}$ grid spacing mesh over the Western U.S., — seven times coarser than the current grid spacing but much finer than the overall global climate model resolution of $\sim 100 \mathrm{~km}$. The topography was smoothed to $28 \mathrm{~km}$, but scaled in height so that the maximum height of the elevation was $3274 \mathrm{~m}$ over the entire western domain (see RUZ for more details on the treatment of topography). As a result of the smoothing, updrafts and downdrafts associated with local peaks and valleys are not properly simulated as discussed by Rasmussen et al. (2011) and noted in RUZ and Chenglai et al. (2018). While snowfall and snowpack may be well simulated over regions on order of 100's of kilometers consistent with the topographic smoothing and model resolution, finer scale snowfall and snowpack are likely not well simulated at $28 \mathrm{~km}$ coarse resolution (Ikeda et al. 2010; Rasmussen et al. 2011, 2014).
The RUZ study focused on the combined dynamical and thermodynamical impacts of climate change on orographic precipitation in the western U.S. through an ensemble of simulations. The interesting result from this study is that they predict the mean ensemble precipitation to increase by $\sim 15 \%$ over the 100 -year future period associated with RCP8.5. The current study estimates precipitation increases of similar magnitude $(\sim 18 \%)$, and thus even though the current results are essentially only one ensemble member representing thermodynamic changes, the overall precipitation enhancement is similar. The unique aspect of our simulation is a focus on resolving mesoscale and microphysical processes, allowing for a reasonable depiction of how current climate snowfall and snowpack may change in the future due to thermodynamic effects. Our future work will extend this approach to at least one other global model ensemble member in order to capture some of the dynamical changes associated with increased GHG effects.

To examine the elevation dependence of the coarse resolution simulations in the $28-\mathrm{km}$ simulations, RUZ interpolated the $28-\mathrm{km}$ output to a $4-\mathrm{km}$ grid in contrast to the current results that directly used dynamically downscaled output at $4 \mathrm{~km}$ without interpolation.

In contrast to the reasonable simulation of snowpack throughout the western U.S. in the present WRF simulation, snowpack is poorly simulated as compared to SNOTEL data in the RUZ study.

The advantage of the variable mesh GCM approach, however, is that many simulations can be performed to sample the natural variability and climate modes of the system. While our study also examined the same RCP8.5 scenario, only one simulation for the future climate was possible due to the large amount of computer time required.

The use of high resolution in the current study was shown to provide excellent estimates of historical climate snowfall and snowpack throughout the domain at fine spatial and vertical resolution as a result of resolving the main topographic 


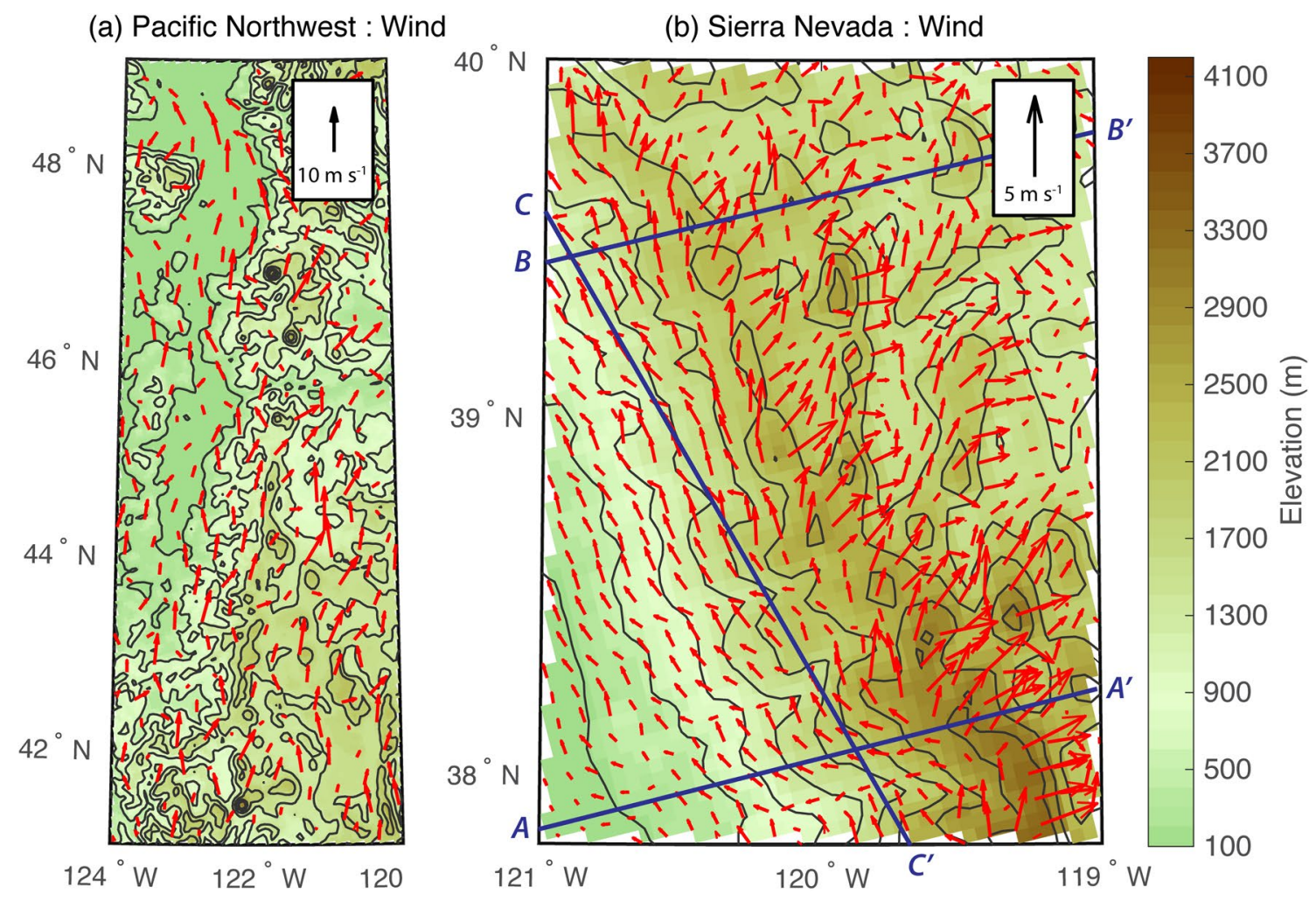

(c) Pacific Northwest : Precipitation
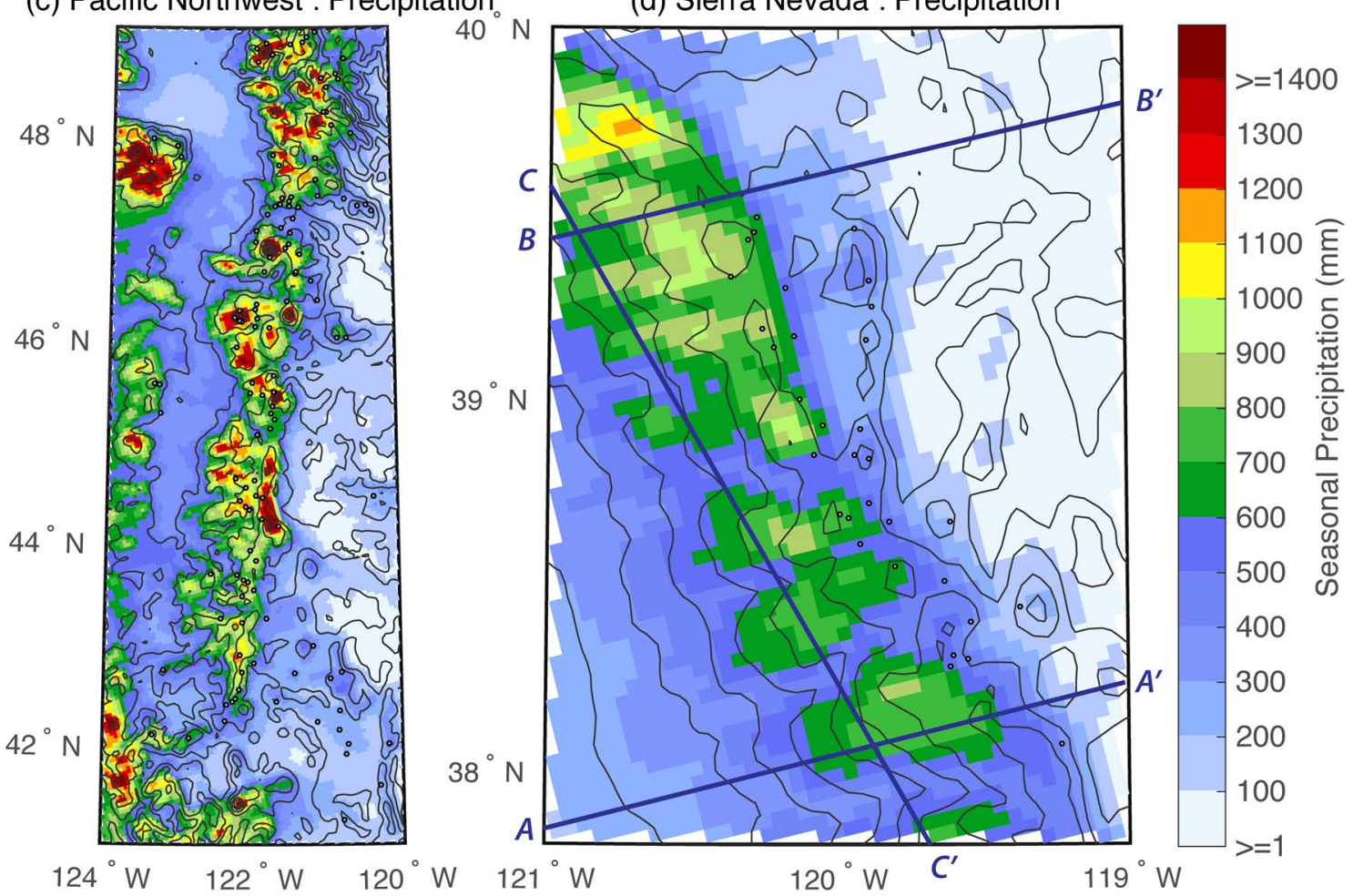

Fig. 11: 13-year average DJF 10-m wind vector from a Pacific Northwest (region 1) and b Sierra Nevada (region 2) and 13-year average DJF precipitation from c Pacific Northwest and d Sierra Nevada.

Cross sections shown for Figs. 12, 13, 14, 15, 16 are overlaid with dark blue lines $\left(\mathrm{A}-\mathrm{A}^{\prime}, \mathrm{B}-\mathrm{B}^{\prime}\right.$, and $\left.\mathrm{C}-\mathrm{C}^{\prime}\right)$ 
Sierra Nevada : W - E Cross Section A-A'
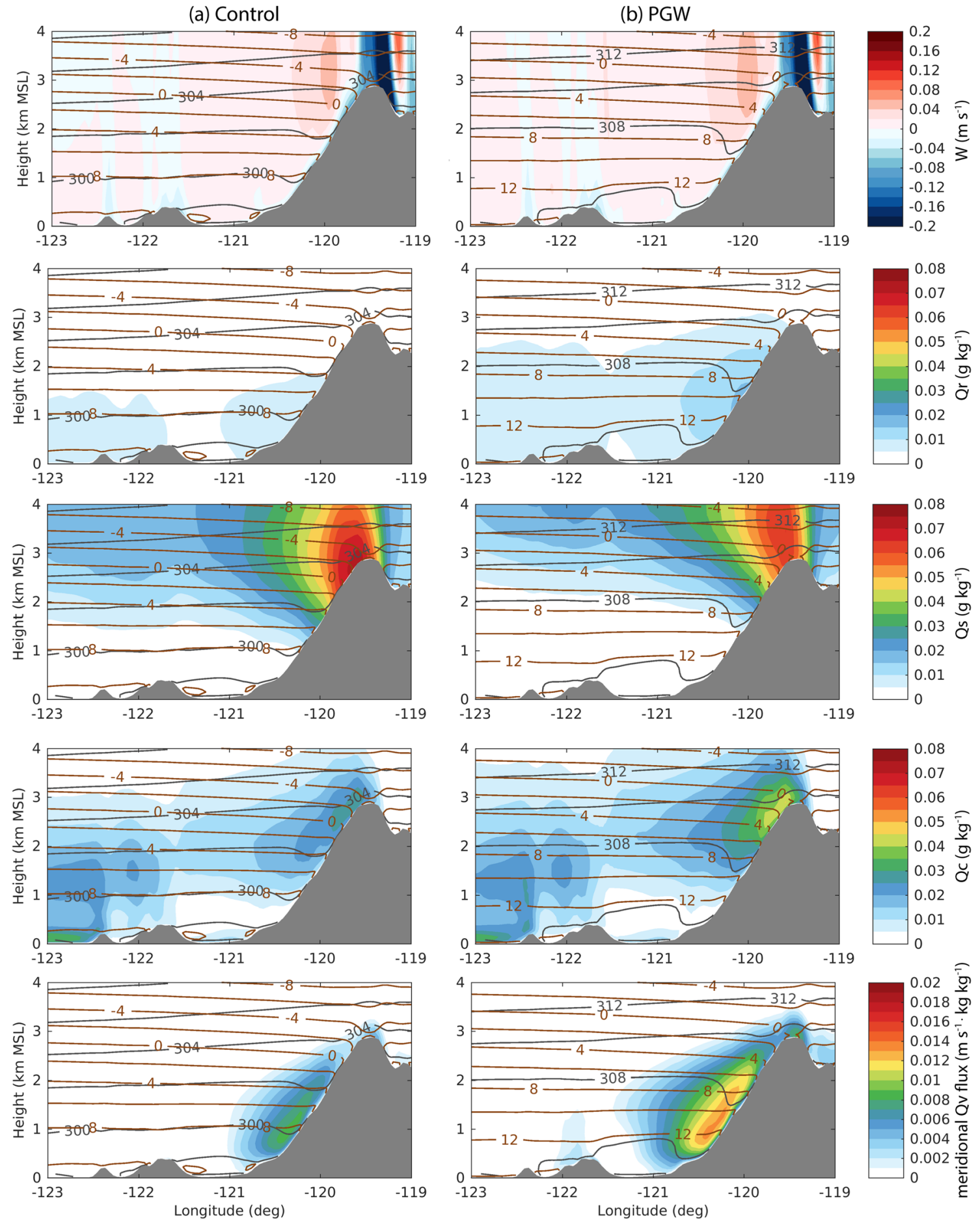

Fig. 12 West-east vertical cross section along A-A' on Fig. 11 showing vertical velocity, rain mixing ratio, snow mixing ratio, cloud mixing ratio, and meridional water vapor flux from a CTRL, and $\mathbf{b}$ PGW

forcings of the snowfall and rainfall (Rasmussen et al. 2011; Beck et al. 2019) and mesoscale processes without interpolation or statistical downscaling, and thus the estimate simulations. All data are average of 13-year period for DJF. Data points $\pm 20 \mathrm{~km}$ in the north-west direction along the cross section have been averaged

for snowfall and snowpack for the chosen future climate is viewed with relatively high confidence.

The future change in April $1^{\text {st }}$ snowpack from the variable GCM over the five Western U.S. mountain ranges that RUZ 


\section{Sierra Nevada : W - E Cross Section B-B'}

(a) Control
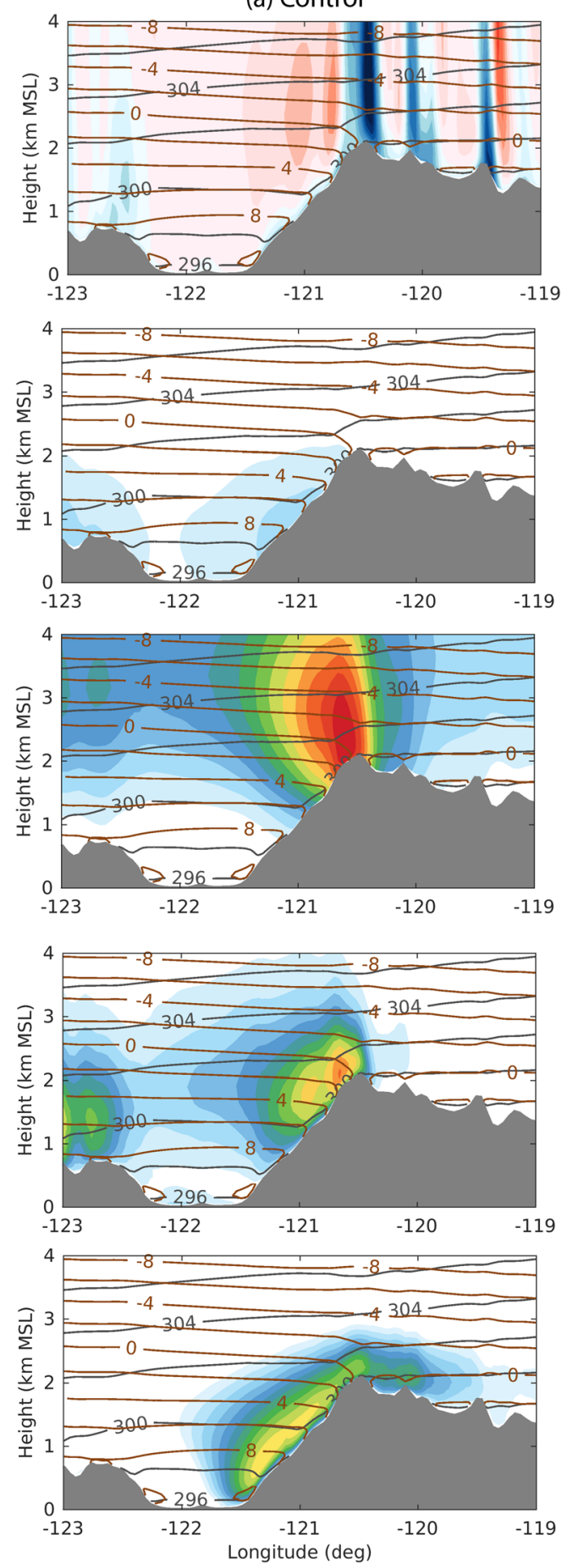

(b) PGW
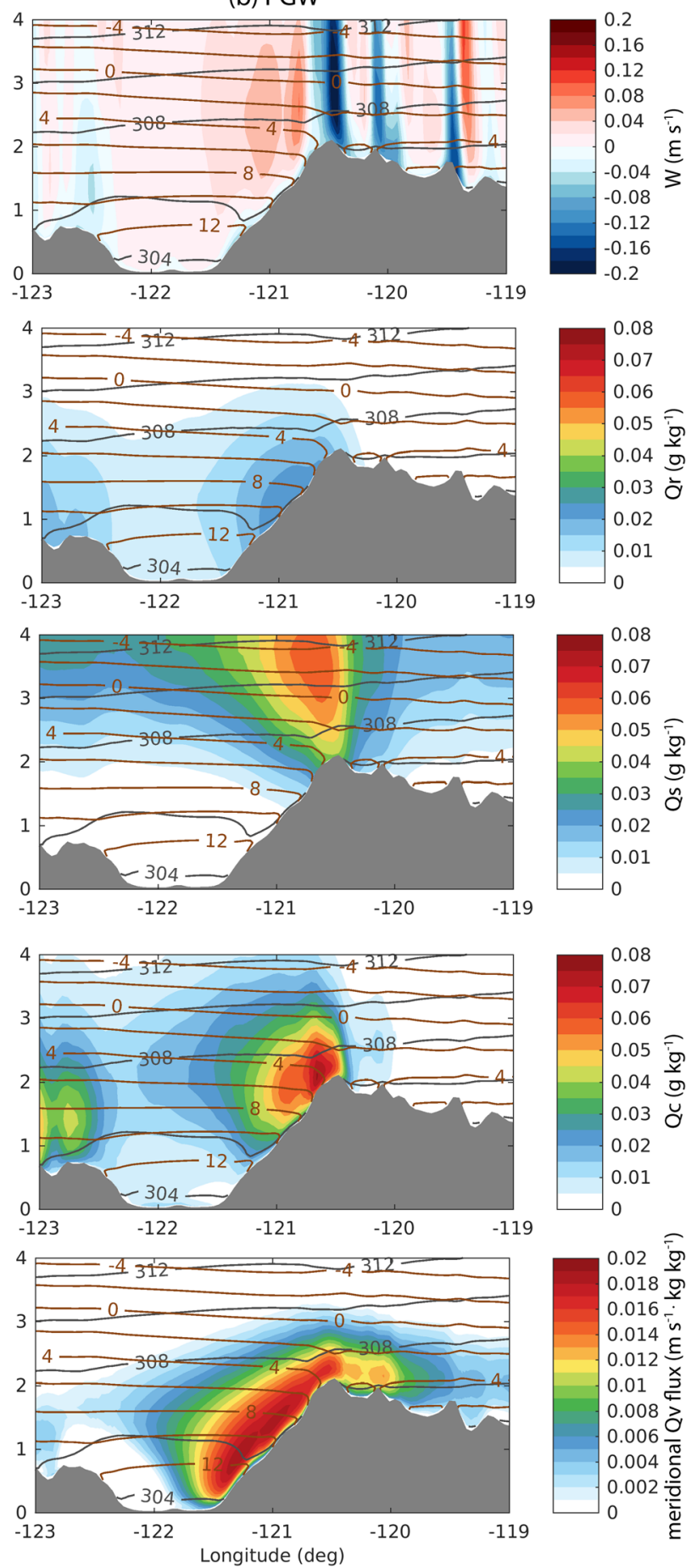

Fig. 13 Same as Fig. 12, but for the northern west-east cross section along B-B' indicated on Fig. 11

defined (slightly different than the current eight ranges) was - 69\% while the current study found between 30 and $70 \%$ decrease in the April 1st snowpack depending on the Range, and similarly in the seasonal peak snowpack for a slightly different definition of eight mountain ranges (Figs. 7, 10).
Thus, while both studies indicate a decrease in snowpack, RUZ estimates a larger decrease than the current results.

Upon further review of the RUZ results in comparison to the current 4-km simulations, we note that the snowfall and snowpack decrease with height in the RUZ simulations with 
Sierra Nevada : NW - SE Cross Section C-C'

(a) Control
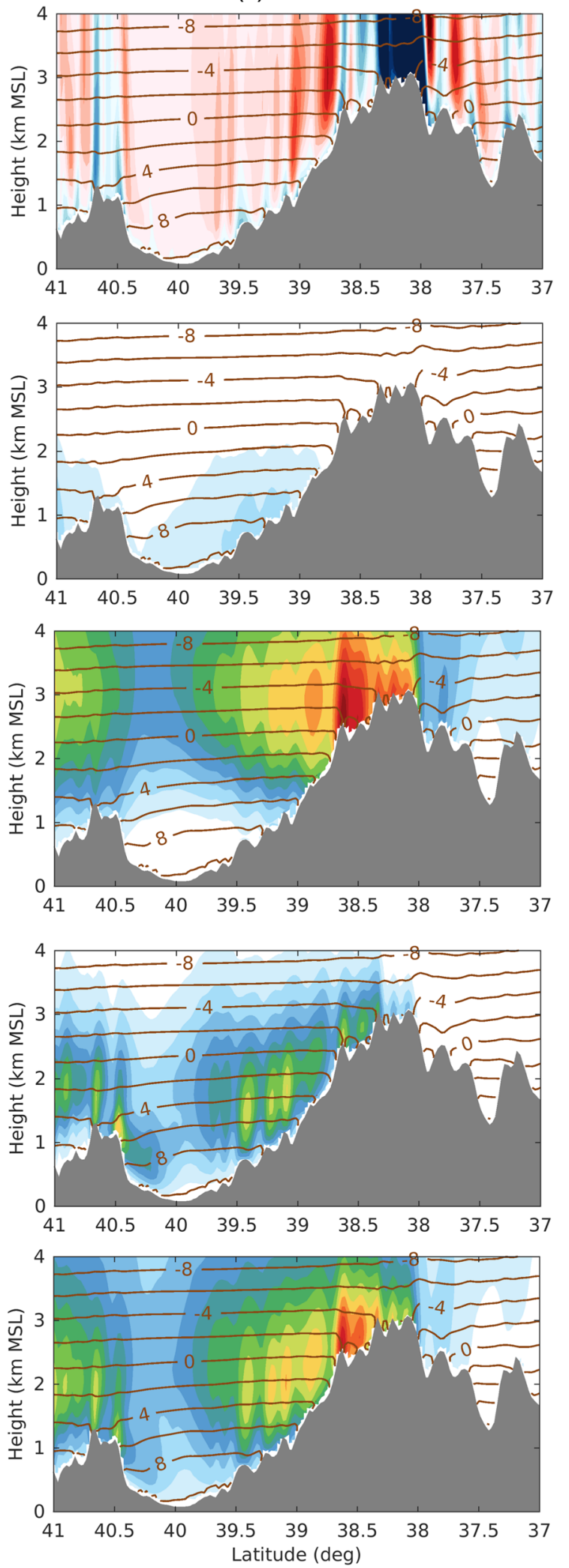

(b) PGW
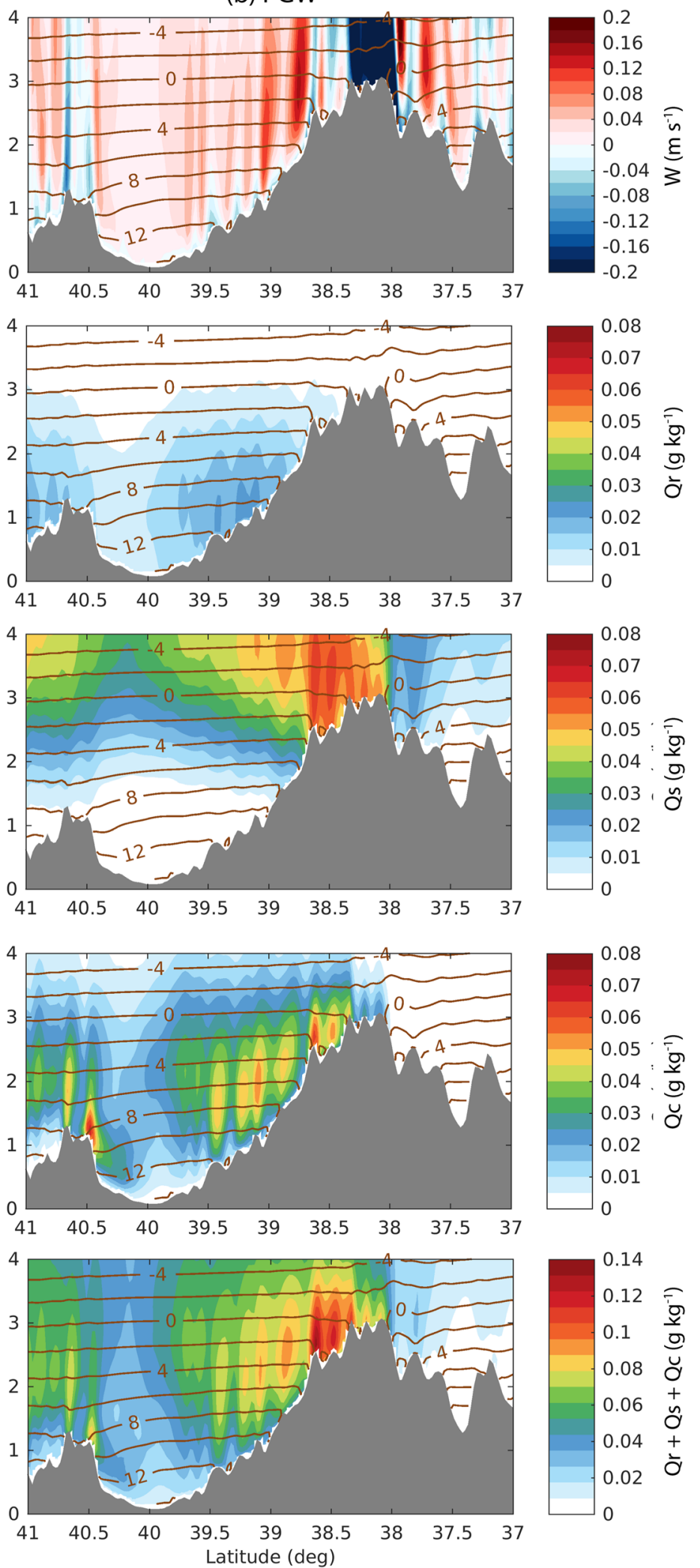

Fig. 14 Same as Fig. 12 but for northwest-southeast transect along C-C' on Fig. 11 and the lowest panels showing total condensate mixing ratio $(\mathrm{Qr}+\mathrm{Qs}+\mathrm{Qc})$. Note that the color scale for the total condensate is not the same as that used for Qs and Qr panels 

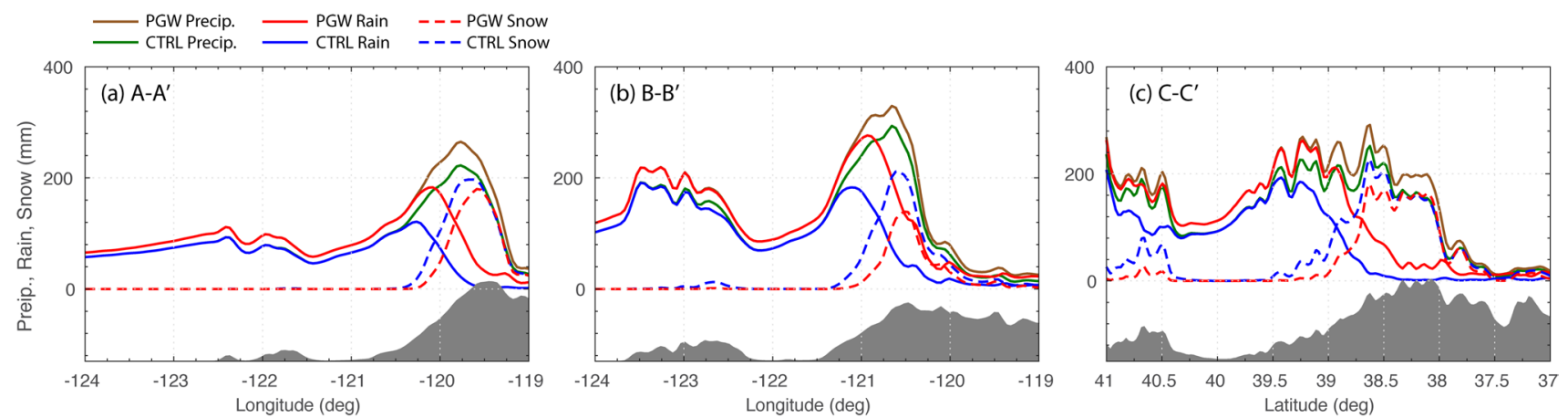

Fig. 15 a-c 13-year average DJF precipitation, rain, and snow from CTRL and PGW along the three transects shown in Fig. 11

a peak near $1000 \mathrm{~m}$ elevation, while in the WRF 4-km simulations snowfall and snowpack increase with height in both current and future simulations, in agreement with observations. If the majority of snowfall and snowpack occurs at lower elevations with higher temperatures, more rapid melting will occur than if the majority of snow was at high elevations where it is colder. This was also noted in RUZ as a problem with their simulations in that too much precipitation was occurring at the leading edge of the topography and not at higher elevations as observed with SNOTEL and PRISM. The cause of this behavior was not given by the authors. As presented in the previous section, the vertical motion associated with the southerly barrier jet flowing over ridges and valleys resolved in the $4 \mathrm{~km}$ simulation causes an enhanced climate change signal over the upstream regions of the Pacific Northwest and Sierra Nevada mountain ranges. This effect is likely not present in the $28-\mathrm{km}$ simulations.

These results show the importance of capturing the physical processes leading to updrafts and downdrafts in complex terrain through appropriately running model simulations at less than $6 \mathrm{~km}$ horizontal grid spacing as shown by Rasmussen et al. (2011) and in the current results.

\section{Conclusions}

This study shows that snowfall and snowpack are well captured at the 4-km horizontal grid spacing through comparison of the 13-year historical simulation to SNOTEL snowfall and snowpack data, providing confidence in the model's ability to capture the dominant precipitation processes in the complex terrain of the western U.S. The analysis of the simulations allows us to draw the following conclusions:

1. The impacts of climate change in the western U.S. can be characterized by considering mountain ranges in two distinct geographic regions: the mountain ranges close to the Pacific Ocean and those in the inter-mountain west. The impact of climate changes out to 2100 is dif- ferent in these two regions and is summarized in the following.

a. Mountain ranges near the Pacific Ocean

By the end of the 21st century, snowpack amount, vertical profile, timing and peak magnitude of runoff are significantly impacted due to the present-day temperatures in these mountain ranges being close to $0{ }^{\circ} \mathrm{C}$ during the winter (Table $3 \mathrm{~b}$ ). As a result, the future temperatures in this region in winter are above $0{ }^{\circ} \mathrm{C}$, leading to significant reductions in the April 1st SWE (Fig. 7) and SWE fraction (Fig. 17) especially in the Pacific Northwest, Sierra Nevada, and Blue Mountains (panels a, b and c in Fig. 17). SWE fraction in Figure 17 is defined as the April 1st SWE divided by the November-March total precipitation, representing the fraction of snowpack compared to total seasonal precipitation (rainfall plus snowfall) surviving by April 1 st. These results show that, the lower elevations with higher temperatures of the west coast ranges are largely devoid of snowpack by April 1st in the future 2100 climate. Since precipitation actually increases in 2100 , the precipitation maximum on the upstream side of the western mountains near the Pacific is mostly rain even in the winter. As a result, enhanced flooding can be expected due to the rapid runoff of the enhanced rainfall as shown in Fig. 16.

The net effect of warming on the mountain ranges along the Pacific Coast is a reduction in maximum snowpack of up to $\sim 70 \%$ and 2-3 months earlier onset of significant runoff.

b. Inter-mountain west ranges

There is a relatively weak impact of climate change on snowpack in the inter-mountain west ranges by the end of the 21 st Century due to the relatively cold wintertime temperatures in the present-day climate $\left(2-5\right.$ degrees below $0{ }^{\circ} \mathrm{C}$; Fig. 10i and Table $3 b$ ). Note that the future climate April 1st 

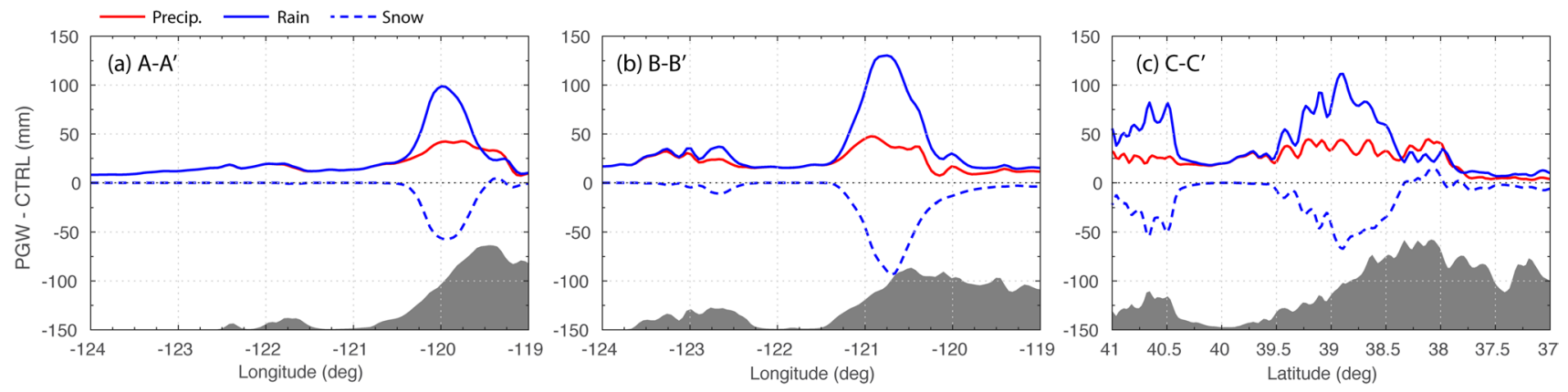

Fig. 16 a-c 13-year average DJF precipitation, rain, and snow change in PGW compared with CTRL along the three transects shown in Fig. 11
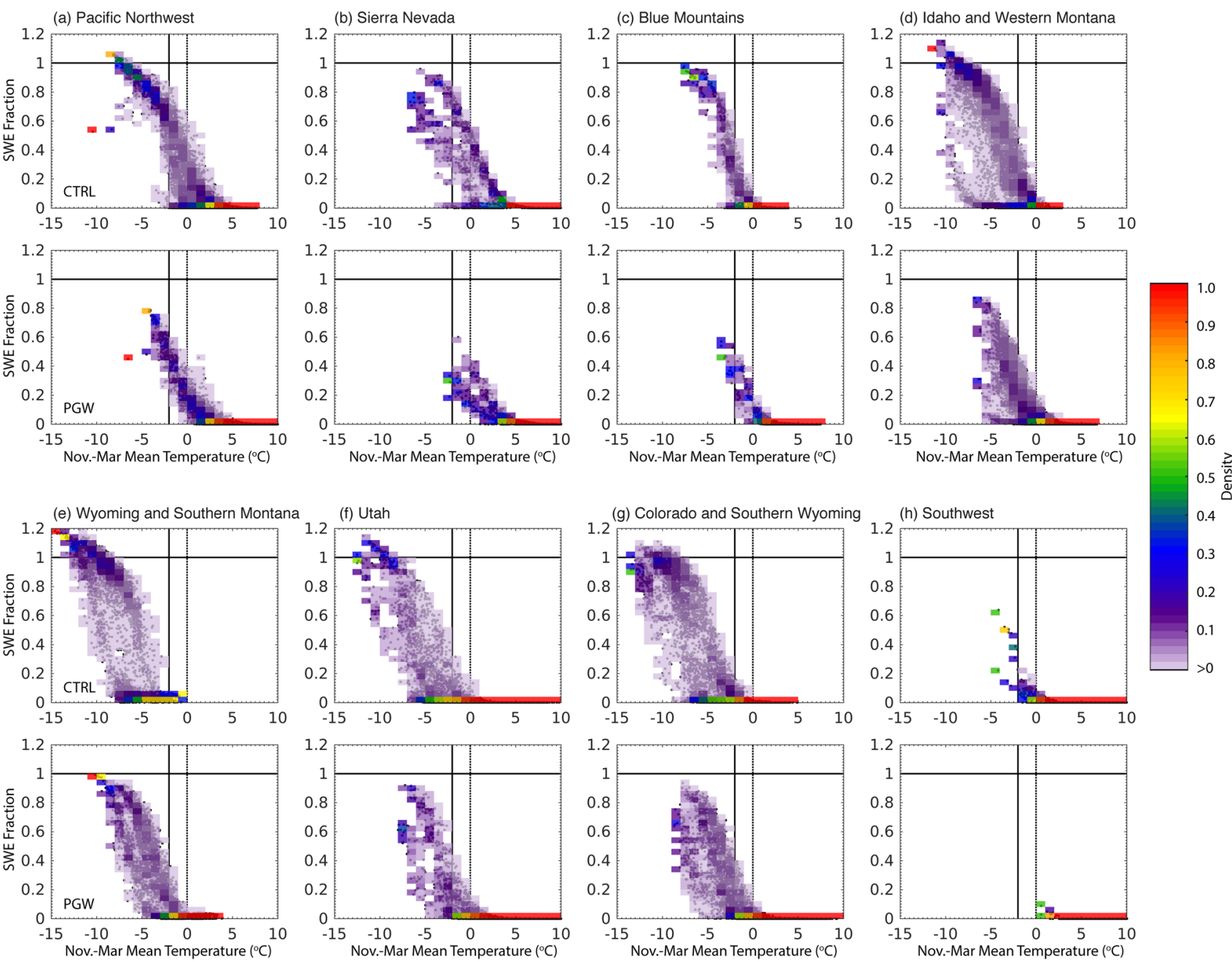

Fig. 17 13-year mean SWE fraction (defined as the April 1st SWE divided by the November-March total precipitation; unitless) plotted as a function of the November-March 13-year mean 2-m temperature for the seven mountain ranges. Dots are the individual grid points in each sub-region. Colors represent density (i.e., fraction) of data points belonging to SWE fraction bins for a given temperature range category. SWE fraction bins are in a increment of 0.04. Temperature categories are in increments of $1{ }^{\circ} \mathrm{C}$. The upper plot for a given figure grouping $(\mathbf{a}-\mathbf{h})$ represents the current climate simulation and the low plot the future PGW simulation. Vertical solid line represents the -2 $\mathrm{C}$ mean temperature while the dashed line the $0{ }^{\circ} \mathrm{C}$ mean temperature snowpack at the majority of high elevation locations (temperatures below $-5{ }^{\circ} \mathrm{C}$ ) in the inter-mountain west ranges (Wyoming, Utah and Colorado) start at SWE fractions between 0.7 and 1.0 in the cur- 
rent climate (Fig. 17e-g) as indicated by the high density of points in that region. In the future climate plot, the SWE curve moves to higher temperatures, however; temperature at these locations is still lower than $0{ }^{\circ} \mathrm{C}$, leading to insignificant snowpack melting and conversion of snowfall to rainfall in these ranges until the spring when temperature climbs above $0{ }^{\circ} \mathrm{C}$ about one month earlier than current climate (Fig. 10). As a result, the SWE fraction does not decrease by April 1st in the future climate as drastically as the coastal mountain ranges. The onset of melting in January results in an earlier peak of runoff by about one month and less runoff in the summer. Change in net annual runoff is near zero.

2. The analysis presented herein suggests that mesoscale updrafts/downdrafts associated with flow of a climatologically dominant southerly barrier jet over east-west oriented river valleys in the Pacific coastal region plays an important role in generating the maximum precipitation along the upstream mountain slope about $2 / 3$ of the distance to the peak, rather than in the region of highest elevation as in the interior western U.S. The barrier jet is associated with the warm frontal portion of extratropical cyclones impacting the Sierra Nevada mountain range.

The current study attempts to address how snowfall and snowpack changes in the western U.S. using a PGW approach with a convection permitting model simulation down to $4 \mathrm{~km}$. In essence, the study answers the question of how the current snowfall and snowpack would look like in a warmer and moister climate. The results indicate that by the year 2100 significant changes will occur to snowfall and snowpack, with larger changes in the mountains close to the Pacific Ocean.

These projected snowfall and snowpack trends have already been observed to occur over the past 50-100 years in the western U.S. (Mote et al. 2005, 2018) in association with a warmer climate and slightly decreasing precipitation. This study suggests that the past trend of declining snowpack and earlier snow melt for the mountains close to the Pacific Ocean will continue to the point that most of the snowpack will be gone by 2100 in the Pacific Northwest for the most aggressive RCP8.5 climate scenario, even if annual precipitation increases by $18 \%$. It should be noted that this study focusses on the thermodynamic impacts of climate change in the western U.S. Future studies high resolution studies are needed to confirm whether this suggestion holds even when dynamical changes to the flow occur.

Acknowledgements The authors acknowledge the support of the NCAR CISL Advanced Scientific Computing Yellowstone Computer allocation that enabled these simulations to be performed. We would like to acknowledge high-performance computing support from Yellowstone (ark:/85065/d7wd3xhc) provided by NCAR's Computational and Information Systems Laboratory, sponsored by the National Science Foundation. We also acknowledge the support of the NCAR Water System program. This material is based upon work supported by the National Center for Atmospheric Research, which is a major facility sponsored by the National Science Foundation under Cooperative Agreement No. 1852977

Open Access This article is licensed under a Creative Commons Attribution 4.0 International License, which permits use, sharing, adaptation, distribution and reproduction in any medium or format, as long as you give appropriate credit to the original author(s) and the source, provide a link to the Creative Commons licence, and indicate if changes were made. The images or other third party material in this article are included in the article's Creative Commons licence, unless indicated otherwise in a credit line to the material. If material is not included in the article's Creative Commons licence and your intended use is not permitted by statutory regulation or exceeds the permitted use, you will need to obtain permission directly from the copyright holder. To view a copy of this licence, visit http://creativecommons.org/licenses/by/4.0/.

\section{References}

Beck HE, Pan M, Roy T, Weedon GP, Pappenberger F, van Dijk AIJM, Huffman GJ, Adler RF, Wood EF (2019) Daily evaluation of 26 precipitation datasets using Stage-IV gauge-radar data for the CONUS. Hydrol Earth Syst Sci 23:207-224. https://doi.org/10. 5194/hess-23-207-2019

Bureau of Reclamation (2012) Colorado river basin water supply and demand study. Final Report. https://www.usbr.gov/lc/region/progr ams/crbstudy/finalreport/index.html. Accessed 7 May 2020

Chen F, Barlage M, Tewari M, Rasmussen R, Jin J, Lettenmaier D, Livneh B, Lin C, Miguez-Macho G, Niu G-Y, Wen L, Yang Z-L (2014) Modeling seasonal snowpack evolution in the complex terrain and forested Colorado Headwaters region: a model intercomparison study. J Geophys Res. https://doi.org/10.1002/2014J D022167

Chenglai W, Liu X, Lin Z, Rhoades AM, Ullrich PA, Zarzycki CM, Lu Z, Rahimi-Esfarjani SR (2018) Exploring a variable-resolution approach for simulating regional climate in the Rocky mountain region using the VR-CESM. J Geo Res Atmos. https://doi.org/10. 1002/2017JD027008

Computational and Information Systems Laboratory (2017) Yellowstone: IBM iDataPlex System (NCAR Community Computing). National Center for Atmospheric Research, Boulder, CO. http:// n2t.net/ark:/85065/d7wd3xhc. Accessed 7 May 2020

Dai A, Rasmussen RM, Liu C, Ikeda K, Prein AF (2017) A new mechanism for warm-season precipitation response to global warming based on convection-permitting simulations. Clim Dyn. https:// doi.org/10.1007/s00382-017-3787-6

Dee D, Uppala S, Simmons A, Berrisford P, Poli P, Kobayashi S, Andrae U, Balmaseda M, Balsamo G, Bauer P et al (2011) The ERA-interim reanalysis: configuration and performance of the data assimilation system. Q J R Meteorol Soc 137:553-597. https://doi.org/10.1002/qj.828

Deser C, Phillips A, Bourdette V, Teng H (2012) Uncertainty in climate change projections: the role of internal variability. Clim Dyn 38:527-546

Garvert MF, Colle BA, Mass CF (2005a) The 13-14 December 2001 IMPROVE-2 event. Part I: Synoptic and mesoscale evolution 
and comparison with a mesoscale model simulation. J Atmos Sci 62:3474-3492

Garvert MF, Woods CP, Colle BA, Mass CF, Hobbs PV, Stoelinga MT, Wolfe JB (2005b) The 13-14 December 2001 IMPROVE-2 event. Part II: comparisons of MM5 Model simulations of clouds and precipitation with observations. J Atmos Sci 62:3520-3534

Gutmann E, Rasmussen R, Liu C, Gochis DJ, Clark M (2012) A Comparison of statistical and dynamical downscaling of winter precipitation over complex terrain. J Clim 25:262-281

Gutmann E, Pruitt T, Clark MP, Brekke L, Arnold JR, Raff DA, Rasmussen RM (2014) An intercomparison of statistical downscaling methods used for water resource assessments in the United States. Water Resour Res 50:7167-7186

Hong SY, Noh Y, Dudhia J (2006) A new vertical diffusion package with an explicit treatment of entrainment processes. Mon Weather Rev 134:2318-2341

Hughes M, Neiman PJ, Sukovich E, Ralph FM (2012) Representation of the Sierra Barrier Jet in 11 years of a high-resolution dynamical reanalysis downscaling compared with long-term wind profiler observations. J Geophys Res Atmos. https://doi. org/10.1029/2012JD017869

Hughes M, Mahoney K, Neiman P, Moore BJ, Alexander M, Ralph FM (2014) The landfall and inland penetration of a floodproducing atmospheric river in Arizona. Part II: sensitivity of modeled precipitation to terrain height and atmospheric river orientation. J Hydromet 15:1954-1974

Iacono MJ, Delamere JS, Mlawer EJ, Shephard MW, Clough SA, Collins WD (2008) Radiative forcing by long-lived greenhouse gases: calculations with the AER radiative transfer models. J Geophys Res Atmos. https://doi.org/10.1029/2008JD009944

Ikeda K, Rasmussen R, Liu C, Gochis D, Yates D, Chen F, Tewari M, Barlage M, Dudhia J, Miller K, Arsenault K, Grubisic V, Thompson G, Gutmann E (2010) Simulation of seasonal snowfall over Colorado. Atmos Res 97:62-477

Kapnick S, Hall A (2012) Causes of recent changes in western North American snowpack. Clim Dyn 38:1885-1899

Liu C, Ikeda K, Thompson G, Rasmussen R, Dudhia J (2011) Highresolution simulations of wintertime precipitation in the Colorado Headwaters region: sensitivity to physics parameterizations. Mon Weather Rev 139:3533-3553

Liu C, Ikeda K, Rasmussen R, Barlage M, Newman AJ, Prein AF, Chen F, Chen L, Clark M, Dai A, Dudhia J, Eidhammer T, Gochis D, Gutmann E, Kurkute S, Li Y, Thompson G, Yates D (2017) Continental-scale convection-permitting modeling of the current and future climate of North America. Clim Dyn. https:// doi.org/10.1007/s00382-016-3327-9

McCrary RR, McGinnis S, Mearns LO (2017) Evaluation of snow water equivalent in NARCCAP simulations, including measures of observational uncertainty. J Hydromet 18:2425-2452. https:// doi.org/10.1175/JHM-D-16-0264.1

Meyer JDD, Jin J, Wang S (2012) Systematic patterns of the inconsistency between snow water equivalent and accumulated precipitation as reported by the Snowpack Telemetry Network. J Hydromet 13:1970-1996

Minder JR, Letcher TW, Skiles SM (2016) An evaluation of highresolution regional climate model simulations of snow cover and albedo over the Rocky Mountains, with implications for the simulated snow-albedo feedback. J Geophys Res Atmos 121:9069-9088

Mote PW, Hamlet AF, Clark MP, Lettenmaier DP (2005) Declining mountain snowpack in western North America. Bull Am Meteorol Soc 86:39-45

Mote PW, Li S, Lettenmaier D, Xiao M, Engel R (2018) Dramatic declines in snowpack in the western U.S. Nature. Clim Atmos Sci. https://doi.org/10.1038/s41612-018-0012-1
Musselman KN, Lehner F, Ikeda K, Clark M, Prein A, Liu C, Barlage M, Rasmussen R (2018) Projected increases and shifts in rain-on-snow flood risk over western North America. Nat Clim Chang 8:808-812

Newman AJ, Clark MP, Craig J, Nijssen B, Wood A, Gutmann E, Mizukami N, Brekke L, Arnold JR (2015) Gridded ensemble precipitation and temperature estimates for the contiguous United States. J Hydromet 16:2481-2500. https://doi.org/10. 1175/JHM-D-15-0026.1

Niu GY, Yang ZL, Mitchell KE, Chen F, Ek MB, Barlage M, Kumar A, Manning K, Niyogi D, Rosero E (2011) The community Noah land surface model with multiparameterization options (Noah-MP): 1. Model description and evaluation with localscale measurements. J Geophys Res Atmos 116:D12109. https:// doi.org/10.1029/2010JD015139

Pavelsky TM, Kapnick S, Hall A (2011) Accumulation and melt dynamics of snowpack from a multiresolution regional climate model in the central Sierra Nevada, California. J Geophys Res Atmos 116:D16115. https://doi.org/10.1029/2010JD01547

Pavelsky TM, Soboloski S, Kapnick S, Barnes J (2012) Changes in orographic precipitation patterns caused by a shift from snow to rain. Geophys Res Lett 39:L18706. https://doi.org/10.1029/2012G L052741

Powers JG et al (2017) The Weather Research and Forecasting Model: overview, system efforts, and future directions. Bull Am Soc 98:1717-1737. https://doi.org/10.1175/BAMS-D-15-00308.1

Prein AF, Holland GJ, Rasmussen RM, Clark MP (2017) The future intensification of hourly precipitation extremes. Nat Clim Chang $7: 48-52$

Rasmussen RM, Smolarkiewicz P, Hall WD, Clark T (1988) Comparison of orographic cloud and precipitation development of three different geographic locations using a 3D nested grid model. In: 10th Int. conf. cloud physics, Bad Homburg, Germany, pp 353-355

Rasmussen R, Liu C, Ikeda K, Gochis DJ, Yates D, Chen F, Tewari M, Barlage M, Dudhia J, Yu W, Miller K, Arsenault K, Grubišić V, Thompson G, Gutmann E (2011) High-resolution coupled climate runoff simulations of seasonal snowfall over Colorado: a process study of current and warmer climate. J Clim 24:3015-3048

Rasmussen R, Baker B, Kochendorfer J, Myers T, Landolt S, Fisher A, Black J, Theriault J, Kucera P, Gochis DJ, Smith C, Nitu R, Hall M, Cristanelli S, Gutmann E (2012) How well are we measuring snow? The NOAA/FAA/NCA winter precipitation test bed. Bull Am Meteorol Soc 93:811-829

Rasmussen R, Ikeda K, Liu C, Gochis D, Clark M, Dai A, Gutmann E, Dudhia J, Chen F, Barlage M, Yates D, Zhang G (2014) Climate change impacts on the water balance of the Colorado Headwaters: high-resolution regional climate model simulation. J Hydromet 15:1091-1116

Rasmussen KL, Prein AF, Rasmussen RM, Ikeda K, Liu C (2017) Changes in the convective population and thermodynamic environments in convection-permitting regional climate simulations over the United States. Clim Dyn. https://doi.org/10.1007/ s00382-017-4000-7

Rhoades A, Ullrich PA, Zarzycki C (2017) Projecting 21st century snowpack trends in western USA mountains using variable-resolution CESM. Clim Dyn. https://doi.org/10.1007/ s00382-017-3606-0

Salzman N, Mearns L (2012) Assessing the performance of multiple regional climate model simulations for seasonal mountain snow in the upper Colorado River Basin. J Hydromet 13:539-556

Schär C, Frie C, Lüthi D, Davies HC (1996) Surrogate climatechange scenarios for regional climate models. Geophys Res Lett 23:669-672

Serreze MC, Clark MP, Armstrong RL, McGinnis DA, Pulwarty RS (1999) Characteristics of the western United Stated snowpack 
from snowpack telemetry (SNOTEL) data. Water Resour Res $35: 2145-2160$

Sun F, Walton D, Hall A (2015) A hybrid dynamical-statistical downscaling technique, part II: End of-century warming projections predict a new climate state in the Los Angeles region. J Clim 28:4618-4636. https://doi.org/10.1175/JCLI-D-14-00197.1

Taylor KE, Stouffer RJ, Meehl GA (2012) An overview of CMIP5 and the experiment design. Bull Am Meteor Soc 93:485-498. https:// doi.org/10.1175/BAMS-D-11-00094.1

Thompson G, Eidhammer T (2014) A study of aerosol impacts on clouds and precipitation development in a large winter cyclone. $\mathrm{J}$ Atmos Sci. https://doi.org/10.1175/JAS-D-13-0305.1

Thompson G, Field PR, Hall WR, Rasmussen RM (2008) Explicit forecasts of winter precipitation using an improved bulk microphysics scheme. Part II: implementation of a new snow parameterization. Mon Weather Rev 136:5095-5115
Weisman ML, Skamarock WC, Klemp JB (1997) The resolution dependence of explicitly modeled convective systems. Mon Weather Rev 125:527-548

Xiao M, Mahanama SP, Xue Y, Chen F, Lettenmaier DP (2021) Modeling snow ablation over the mountains of the Western United States: patterns and controlling factors. J Hydrometeor 22:297-331

Yang D, Goodison BE, Metcalfe JR, Golubev VS, Bates R, Pangburn T, Hanson CL (1988) Accuracy of NWS 8" standard nonrecording precipitation gauge: results and application of WMO intercomparison. J Atmos Ocean Tech 15:54-68

Publisher's Note Springer Nature remains neutral with regard to jurisdictional claims in published maps and institutional affiliations. 